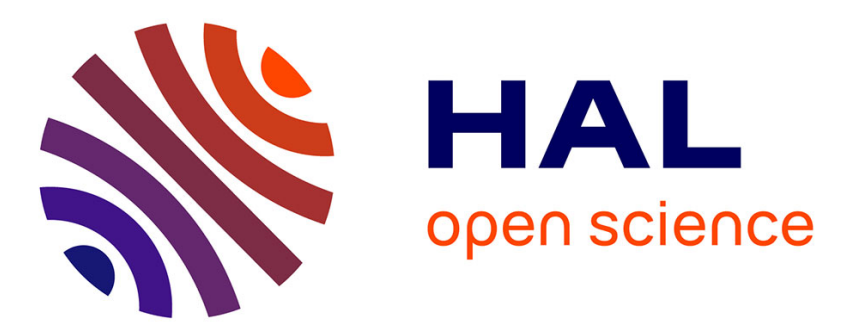

\title{
On the Coupling between Recrystallization and Precipitation Following Hot Deformation in a $\gamma-\gamma$ ' Nickel-Based Superalloy
}

Anthony Seret, Charbel Moussa, Marc Bernacki, Nathalie Bozzolo

\section{To cite this version:}

Anthony Seret, Charbel Moussa, Marc Bernacki, Nathalie Bozzolo. On the Coupling between Recrystallization and Precipitation Following Hot Deformation in a $\gamma-\gamma^{\prime}$ Nickel-Based Superalloy. Metallurgical and Materials Transactions A, 2018, 49 (9), pp.4199-4213. 10.1007/s11661-018-4707-z . hal-01817936

\section{HAL Id: hal-01817936 \\ https://hal.science/hal-01817936}

Submitted on 18 Jun 2018

HAL is a multi-disciplinary open access archive for the deposit and dissemination of scientific research documents, whether they are published or not. The documents may come from teaching and research institutions in France or abroad, or from public or private research centers.
L'archive ouverte pluridisciplinaire HAL, est destinée au dépôt et à la diffusion de documents scientifiques de niveau recherche, publiés ou non, émanant des établissements d'enseignement et de recherche français ou étrangers, des laboratoires publics ou privés. 


\title{
On the coupling between recrystallization and precipitation following hot deformation in a $\gamma-\gamma^{\prime}$ Nickel-based superalloy
}

\author{
Anthony SERET, Charbel MOUSSA, Marc BERNACKI, Nathalie BOZZOLO \\ MINES ParisTech, PSL - Research University, \\ CEMEF - Centre de mise en forme des matériaux, \\ CNRS UMR 7635, CS 10207 rue Claude Daunesse \\ 06904 Sophia Antipolis Cedex, France.
}

\begin{abstract}
Post-dynamic recrystallization and $\gamma^{\prime}$ precipitation during cooling from $\gamma^{\prime}$ supersolvus temperature after hot compression have been studied in the $\mathrm{AD} 730^{\mathrm{TM}} \gamma-\gamma^{\prime}$ Nickel-based superalloy. Emphasis was given not only on both phenomena as distinct mechanisms but also on their mutual influence in terms of physical mechanisms. The growth of $\gamma^{\prime}$ precipitates is hastened in the unrecrystallized grains compared to the recrystallized ones. This could possibly be attributed to the higher dislocation content acting as highdiffusivity paths. Post-dynamic recrystallization is not prevented by Smith-Zener pinning of the recrystallization front by the $\gamma$ ' precipitates. Instead, the recrystallization front dissolves $\gamma^{\prime}$ precipitates which then reprecipitate discontinuously or continuously, and coherently with the surrounding $\gamma$ matrix in the recrystallized grains.
\end{abstract}

\section{Introduction and motivation}

$\gamma-\gamma^{\prime}$ Nickel-based superalloys designed for high temperature turbine disks are strengthened by $\gamma^{\prime}-\mathrm{Ni}_{3}(\mathrm{Al}, \mathrm{Ti})$ precipitates. In-service properties are controlled by grain structure and $\gamma^{\prime}$ precipitation, which both are dependent on the thermo-mechanical processing conditions. Hot-forging is operated at temperatures where $\gamma^{\prime}$ precipitates are partially or fully dissolved. Fine $\gamma$ ' precipitates form again during cooling, with a size distribution which depends on the cooling rate. Thus, the fine $\gamma^{\prime}$ precipitation is mainly 
controlled by the cooling conditions, while the grain structure is controlled by dynamic and post-dynamic recrystallization occurring during hot forging and cooling, respectively.

Kinetics of static [1], dynamic [2, 3, 4, 5, 6, 7], and post-dynamic [8, 9, 10] recrystallization in Nickel-based superalloys have already been addressed in the literature. Kinetics of $\gamma^{\prime}$ precipitation have been studied under different thermal paths, including isothermal aging treatment $[11,12,13]$, isothermal solution treatment [14], multiple isothermal solution treatments and isothermal aging treatments with different cooling rates [15], and cooling from $\gamma^{\prime}$ supersolvus temperature with different cooling rates and quenching temperatures [16].

During cooling after hot-deformation, both post-dynamic recrystallization and $\gamma$ ' precipitation take place and may influence each other. For example, dislocations can promote precipitation in many alloys $[17,18]$ including Ni-based superalloys [19, 20]. Moreover, coherent $\gamma$ ' precipitates can hinder dislocation glide [21] and thus slow down recovery and/or nucleation of new recrystallized grains during cooling. Eventually, Smith-Zener pinning can also influence post-dynamic recrystallization kinetics [22].

Therefore, reliable prediction of the microstructure obtained after a hot-forging sequence not only implies the knowledge of post-dynamic recrystallization and $\gamma^{\prime}$ precipitation kinetics separately, but also their mutual interactions. The aim of this work is to better understand the coupling between the features related to the recrystallization state (i.e. dislocations stored in the microstructure after hot deformation, grain boundaries and recrystallization front), and the $\gamma^{\prime}$ precipitation state.

\section{Experimental procedure}

The experimental plan schematized on Figure 1 is designed to onset dynamic recrystallization during a supersolvus hot-deformation and then to follow the microstructure evolution upon slow cooling. After hot deformation, the material is thus slowly cooled down to different quenching temperatures. Finally, water quenching is 
performed to provide a snapshot of the current material at each of those quenching temperatures. The goal is to depict the complete sequence of post-dynamic recrystallization, $\gamma^{\prime}$ precipitation and their interactions during cooling.

The material used is this work is the $\mathrm{AD} 730^{\mathrm{TM}}$ alloy [11], designed by the Aubert \& Duval company as a cost-effective Nickel-based superalloy for high-temperature turbines disks of aircraft engine. Five cylindrical specimens of $8 \mathrm{~mm}$ diameter and $12 \mathrm{~mm}$ height were cut out. They will be denoted as $\mathrm{A}, \mathrm{q}_{1125}, \mathrm{q}_{1075}, \mathrm{q}_{1000}$ and $\mathrm{q}_{400}$ and the corresponding thermomechanical paths summarized on Figure 1 are defined as follows:

1) Thermal treatment for $2 \mathrm{~h} 20 \mathrm{~min}$ at $1125^{\circ} \mathrm{C}$ (slightly above the $\gamma^{\prime}$ solvus temperature which is close to $1120^{\circ} \mathrm{C}[16]$ ) to remove dislocations by static recrystallization and/or recovery and to dissolve the $\gamma^{\prime}$ phase in order to start from a well-controlled material free of both dislocations and $\gamma^{\prime}$ precipitates while avoiding exaggerated grain growth. The uncertainty of the used thermocouple is $5^{\circ} \mathrm{C}$. Sample A was water quenched at the end of this thermal treatment and contained equiaxed grains with a mean equivalent diameter above $500 \mu \mathrm{m}$.

2) Uniaxial compression to mid-height (thus to macroscopic Von Mises equivalent plastic strain of 0.69) at a Von Mises equivalent plastic strain rate of $10^{-2} \mathrm{~s}^{-1}$ at $1125^{\circ} \mathrm{C}$ to onset dynamic recrystallization and thus to obtain two types of grains: recrystallized ones with a low dislocation content and unrecrystallized ones with a higher dislocation content. The tests were performed on a MTS Landmark machine and the tools-cylinder contacts were lubricated with boron nitride.

3). Cooling after step 2 differs between all four specimens. The $\mathrm{q}_{1125}$ sample was water quenched immediately after deformation to freeze the dynamic recrystallization state (the actual experimental quenching delay is 3-5 sec). The $\mathrm{q}_{1075}, \mathrm{q}_{1000}$ and $\mathrm{q}_{400}$ samples were slow cooled down to $1075^{\circ} \mathrm{C}, 1000^{\circ} \mathrm{C}$ and $400^{\circ} \mathrm{C}$ respectively at $19.5^{\circ} \mathrm{C} / \mathrm{min}$ and then water quenched. 


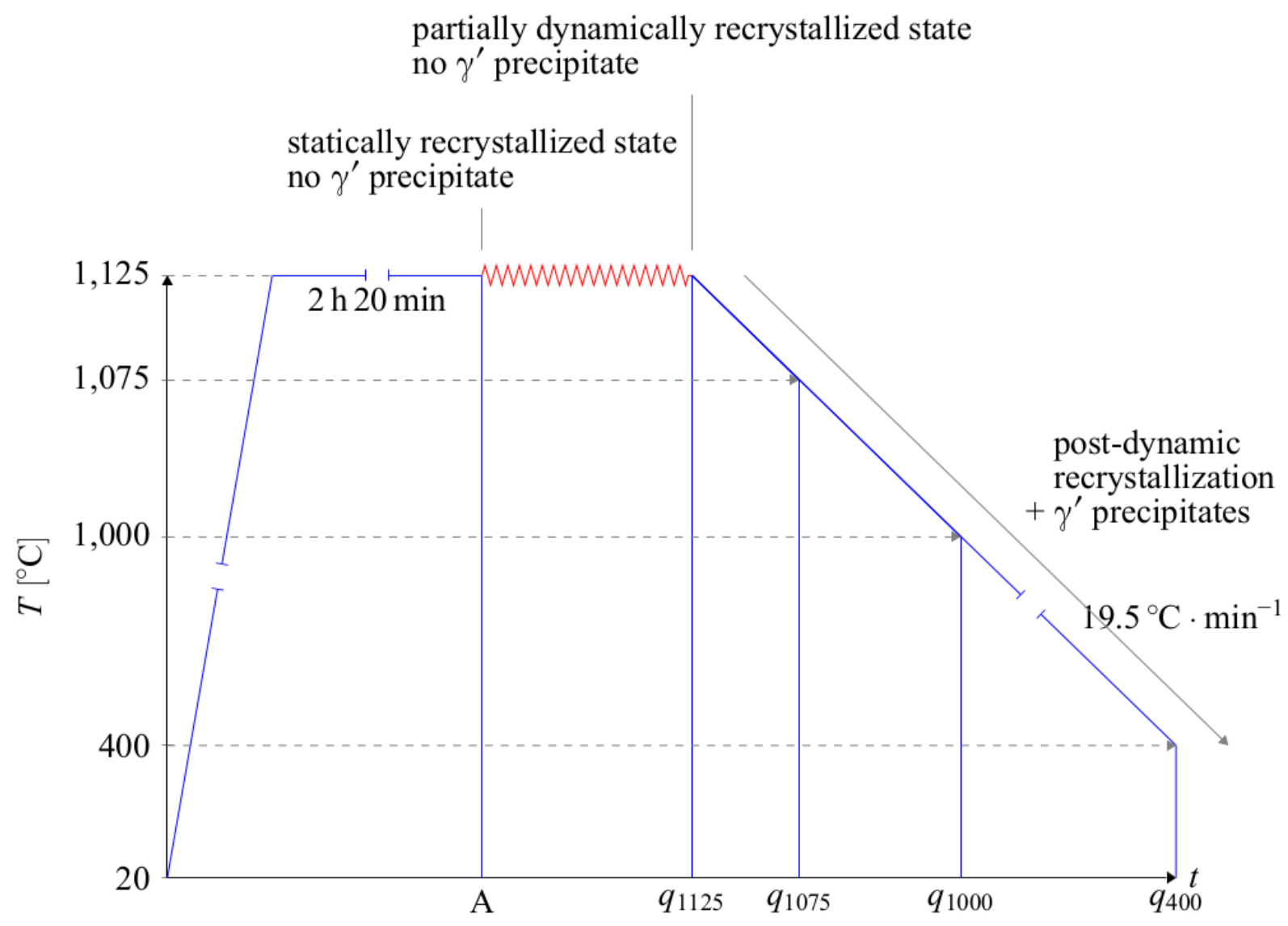

Figure 1: thermomechanical path applied to produce the five studied samples.

For each sample, two metallographic preparations were performed depending on the targeted analysis. Both preparations started with cutting along a longitudinal plane followed by mechanical polishing with abrasive papers \#600 to 4000 . Then diamond suspension solutions ( 3 and then $1 \mu \mathrm{m}$ ) and eventually colloidal silica were used for finishing. The preparation was stopped here for characterizing the microstructures in terms of recrystallization and precipitation, but to quantify small $\gamma$ ' precipitates -whose mean equivalent diameter is typically below $100 \mathrm{~nm}$ - samples were further etched with regia water ( $3 / 4 \mathrm{HCl}, 1 / 4 \mathrm{HNO}_{3}$ in volume) during 3 to 5 seconds. This etching dissolves $\gamma$ ' precipitates. 
Samples were observed on a Carl Zeiss Supra 40 FEG-SEM (Field Emission Gun Scanning Electron Microscope) controlled with the SmartSEM software package and equipped with a Quantax EBSD (Electron Backscatter Diffraction) system from the Bruker company, comprising an $\mathrm{e}^{-}$Flash $^{\mathrm{HR}}$ camera and the Esprit 1.9 software package. All analyses were located in a $1.7 \mathrm{~mm}$ by $2.3 \mathrm{~mm}$ rectangular area at the sample center, the length and width of the rectangle being respectively orthogonal and parallel to the compression direction. Recrystallized fractions and equivalent diameters of recrystallized grains were estimated from EBSD data covering that $1.7 \mathrm{~mm}$ by $2.3 \mathrm{~mm}$ rectangular area at the sample center, with $2 \mu \mathrm{m}$ step size on a square grid. Grains were defined by a disorientation threshold of $10^{\circ}$, and a double criterion based on a grain average misorientation (GAM) threshold and an equivalent diameter threshold was applied to discriminate recrystallized and unrecrystallized grains. For each sample, 5 images were analyzed (accounting for $82 \mu \mathrm{m}^{2}$ total area). Among all measured precipitate size distributions, a minimum of $438 \gamma^{\prime}$ precipitates was considered. The uncertainty of the equivalent diameter of a particle is considered to be twice (for both sides of the segmented particle border) the edge length of a pixel of digital images (absolute error normal to the particle border), that is $9.0 \mathrm{~nm}$. This uncertainty is also considered for the average values provided below and summarized in Figure 15b.

All specimens were then observed at different magnifications depending on the seeked information. Low magnification backscattered electron (BSE) images allowed to globally describe microstructures and recrystallization states (complementary to EBSD scans). Intermediate magnification BSE images were used to observe $\gamma^{\prime}$ precipitates in recrystallized and in unrecrystallized areas. High magnification SE images allowed to both better depict the morphology of fine $\gamma^{\prime}$ precipitates and to quantify their sizes (equivalent disk diameters) by digital image processing. 


\section{Microstructure evolution during slow cooling after supersolvus deformation.}

\subsection{Analysis of the sample $q_{1125}$ quenched immediately after deformation}
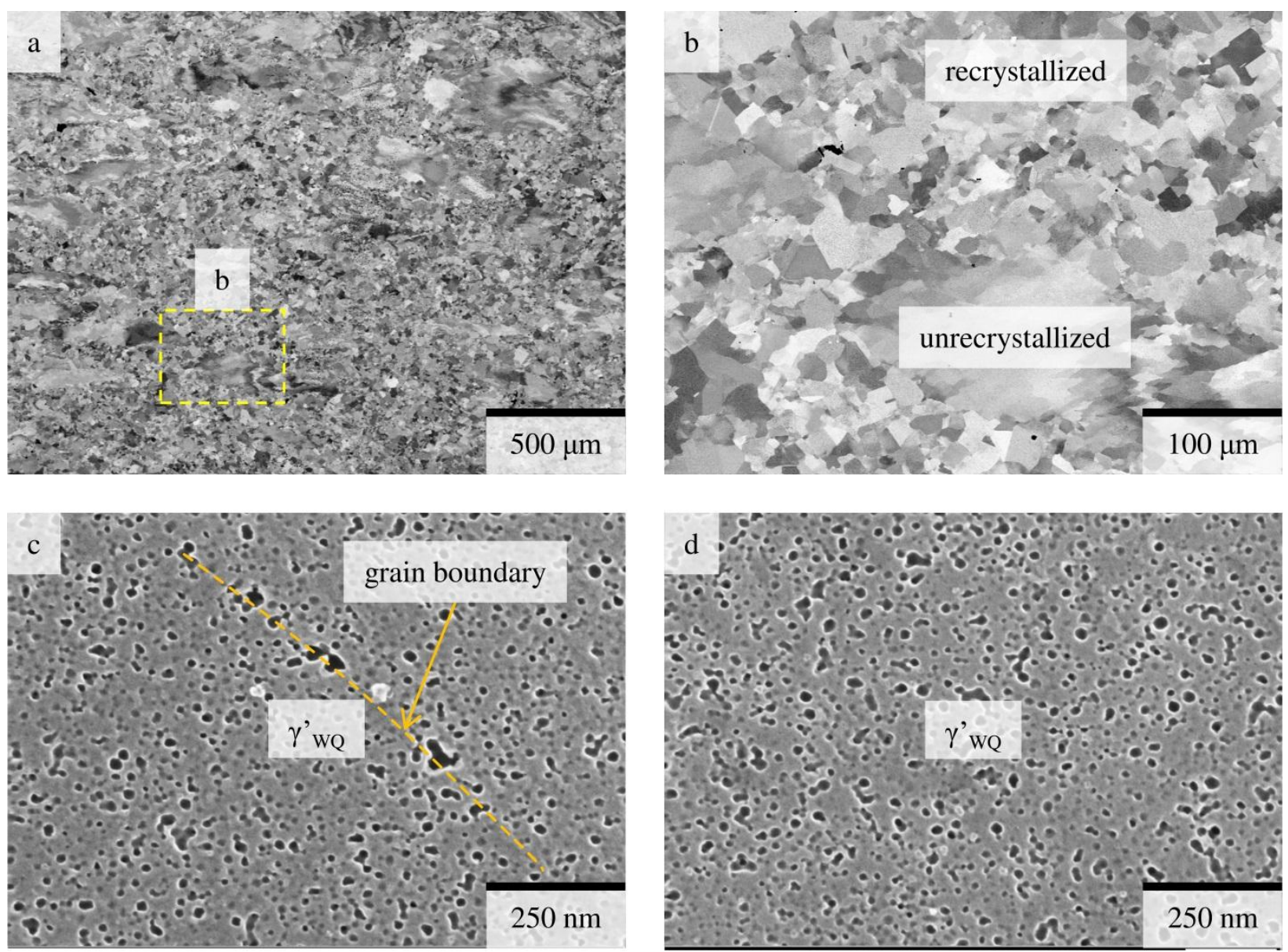

Figure 2: SEM characterization of the sample $\mathrm{q}_{1125}$ (the compression direction is vertical).

BSE images showing (a) an overview of the microstructure,

(b) recrystallized and unrecrystallized areas (zoom into the rectangular area shown on (a))

SE images showing $\gamma^{\prime}$ precipitates in (c) recrystallized and (d) unrecrystallized areas.

Figure 2 shows the microstructure of the sample quenched immediately after hotdeformation (actually with an experimental quenching delay of 3-5 sec). The overview of Figure $2 \mathrm{a}$ and Figure $2 \mathrm{~b}$ show unambiguously that the material has partially recrystallized. Unrecrystallized areas exhibit typical flattened deformation substructures orthogonal to the compression direction and recrystallized grains have rather equiaxed 
shapes and sharp boundaries. Unrecrystallized grains have heterogeneous crystallographic orientations as a result of the accumulated plastic deformation, leading to BSE intensity fluctuations (or electron channeling contrasts). The recrystallized grains generally have a rather homogeneous crystal orientation (and thus BSE intensity), but few of them nevertheless present some heterogeneity of crystallographic orientation. Those ones could have grown during hot deformation (i.e. dynamically) or have been plastically dformed during quenching, while those with an homogeneous crystallographic orientation are likely to be post-dynamically grown (i.e. they grew during the short actual quenching delay of 3-5 s after the deformation) and did not plastify during quenching. Quantitative analysis yields a $45 \%$ recrystallized fraction and a $17 \mu \mathrm{m}$ mean equivalent diameter for the recrystallized grains. Regarding $\gamma^{\prime}$ precipitation, Figure 2(c, d) reveal fine $\gamma^{\prime}$ precipitates (in the range $\sim 10-30 \mathrm{~nm}$ ) which formed both in recrystallized and in unrecrystallized areas despite the fast cooling (water quenching) from the $\gamma^{\prime}$ supersolvus temperature. Those $\gamma$ ' precipitates are then denoted as $\gamma^{\prime}$ WQ, where "WQ" stands for "water quench". The $\gamma$ ' precipitation, despite water quenching, is consistent with similar observations reported on the same alloy [16]. Noteworthy the biggest $(\sim 30 \mathrm{~nm}) \gamma^{\prime}$ precipitates of Figure $2 \mathrm{c}$ are on a grain boundary. This suggests that grain boundaries hasten growth of $\gamma^{\prime}$ precipitates in recrystallized areas, probably through enhanced solute (Al, Ti) diffusion along the grain boundary or solute segregation on grain boundaries. Here it is worth pointing out that in this sample quenched from the supersolvus deformation temperature, $\gamma$ ' precipitates formed during water-quenching in a pre-existing grain structure, developed during and after deformation at $1125^{\circ} \mathrm{C}$. 


\subsection{Analysis of the sample $q_{1075}$ quenched after slow cooling down to $1075^{\circ} \mathrm{C}$}
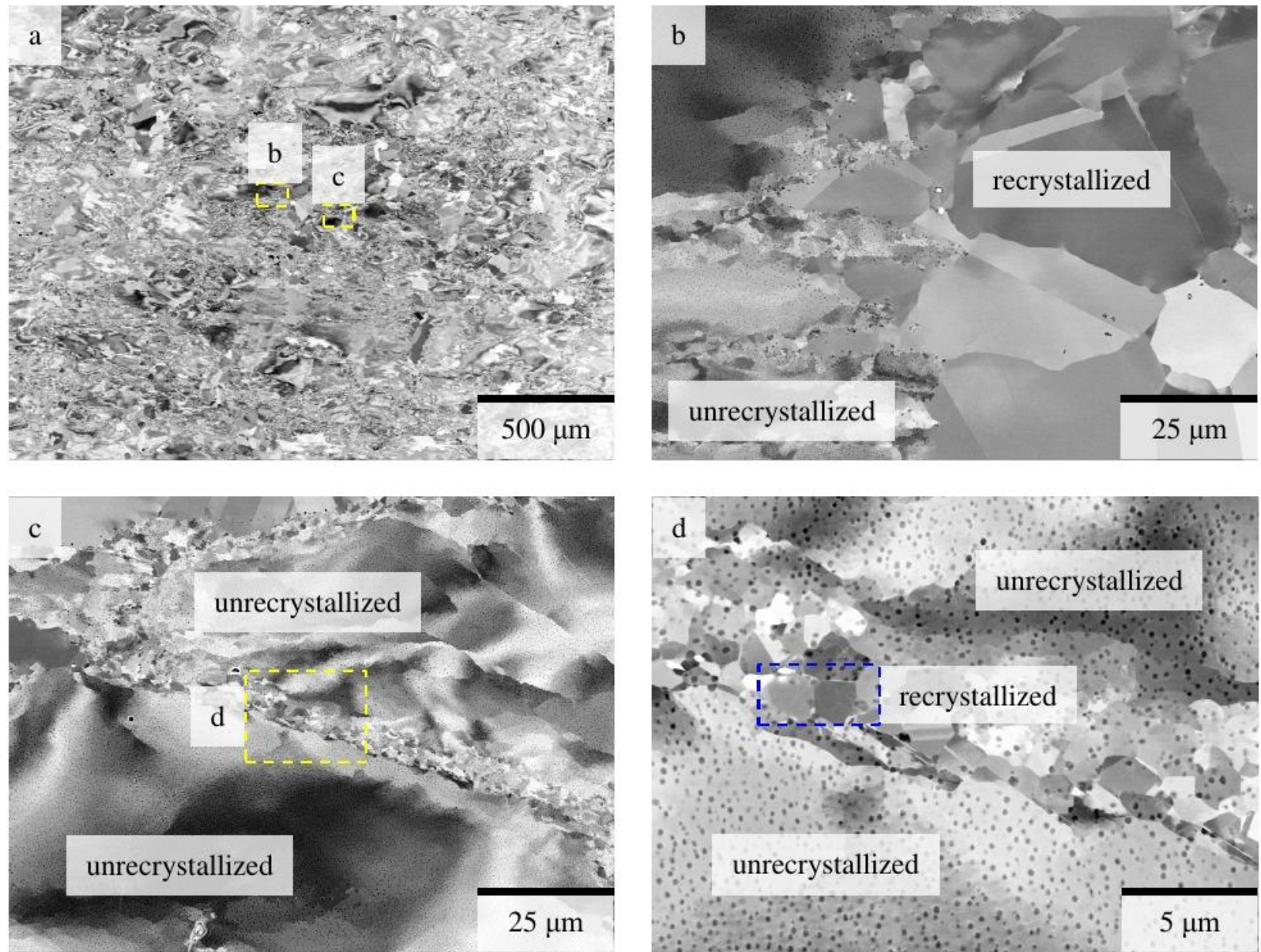

Figure 3: BSE images of the sample $\mathrm{q}_{1075}$ (the compression direction is vertical) showing (a) an overview of the microstructure, (b) recrystallized and unrecrystallized areas,

(c) bands of statically recrystallized grains during the cooling surrounded by unrecrystallized areas,

(d) a band of statically recrystallized grains during the cooling and $\gamma^{\prime}$ precipitates in the surrounding unrecrystallized areas

After slow cooling to $1075^{\circ} \mathrm{C}$, the microstructure is partially recrystallized (Figure 3(a, b)), but surprisingly the recrystallization fraction is $17 \%$; lower than the one observed after immediate quenching (Figure 2(a,b)). Experimental error sources could be responsible for these surprising results. The temperature control as well as the 
displacement control may vary from test to test and thus impact the dynamic recrystallization process and subsequently the recrystallized fractions. As a consequence, the values of recrystallized fractions must be interpreted carefully.

The mean recrystallized grain size of the sample $\mathrm{q}_{1075}$ is $18 \mu \mathrm{m}$. The $\mathrm{q}_{1075}$ microstructure contains quite large post-dynamically recrystallized grains (Figure $3 b$ ) similar to the ones in $\mathrm{q}_{1125}$ (Figure $2 \mathrm{~b}$ ).

The microstructure also contains much smaller recrystallized grains $(\sim 2 \mu \mathrm{m}$, Figure 3(c, d)), which are most likely to be statically recrystallized ones. The assumption behind that is that they nucleated at the boundaries of unrecrystallized grains during cooling and had not much time to grow before quenching. Note that these grains are not taken into account in the calculation of the recrystallized fraction since they were not captured by the EBSD scan, as the step size $(2 \mu \mathrm{m})$ was similar to their size. These grains are equiaxed and present homogeneous BSE signal which suggest that their crystallographic orientation is uniform and thus contain a low dislocation content, which is consistent with the idea that they nucleated and grew after the hot deformation. 

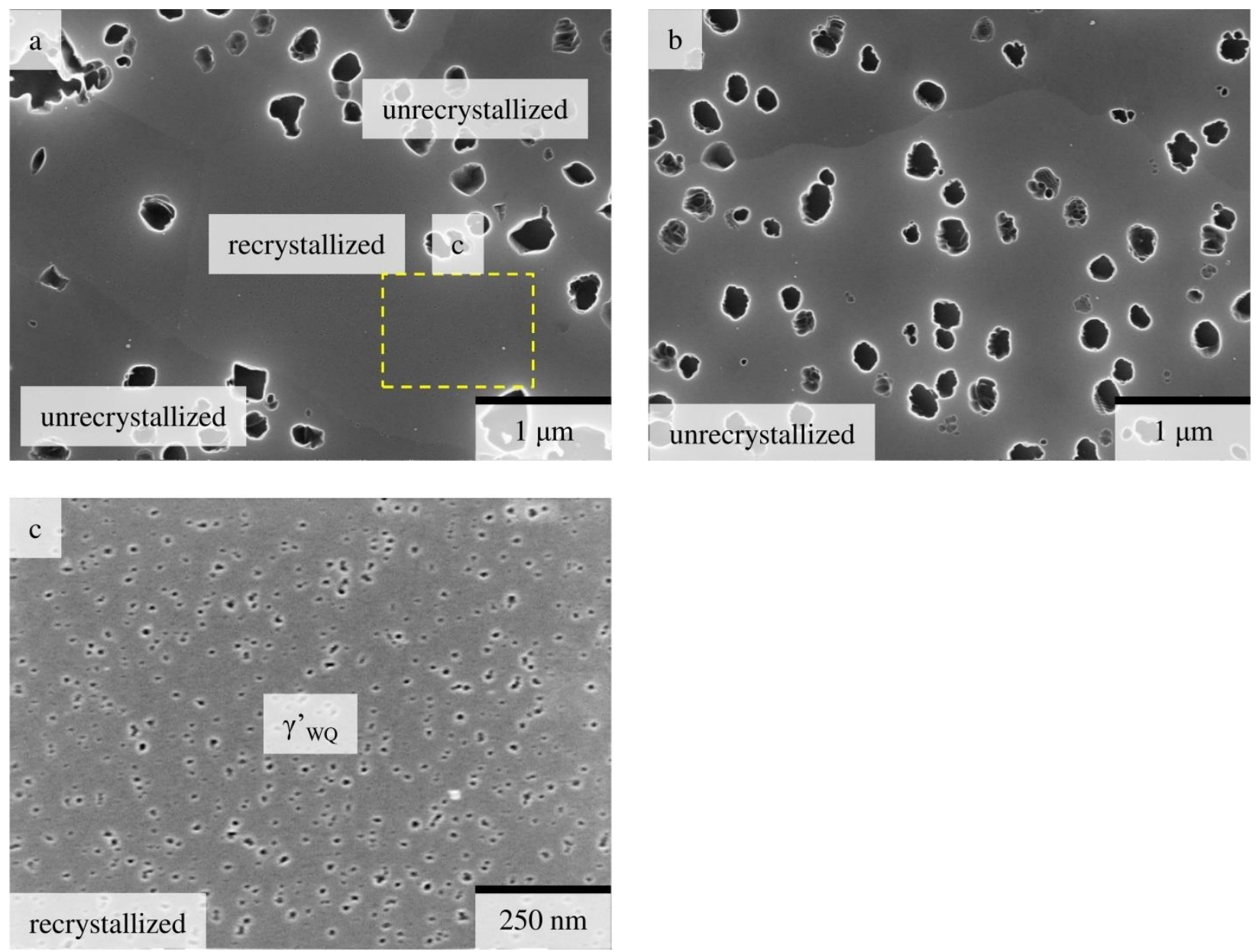

Figure 4: SE images of the sample $\mathrm{q}_{1075}$ (the compression direction is vertical), showing (a) $\gamma^{\prime}{ }_{1075 \mathrm{NR}}$ precipitates in unrecrystallized areas surrounding recrystallized grains, (b) $\gamma^{\prime}{ }_{1075 \mathrm{NR}}$ precipitates in an unrecrystallized area,

(c) $\gamma^{\prime}{ }_{W Q}$ precipitates inside a statically post-dynamically recrystallized grain resulting from the water quench.

Regarding $\gamma$ ' precipitation, two regions are defined:

(1) in the unrecrystallized area, globular and regularly spaced $\gamma$ ' precipitates with 130 $\mathrm{nm}$ mean equivalent diameter, are denoted $\gamma^{\prime}{ }_{1075 \mathrm{NR}}$ (Figure $3 \mathrm{c}$ and Figure 4(a,b)), where "NR" stands for "non recrystallized",

(2) inside recrystallized grains, $\sim 20 \mathrm{~nm} \gamma^{\prime}$ precipitates which probably formed during the water quenching from $1075^{\circ} \mathrm{C}$ are denoted $\gamma^{\prime}{ }_{\text {wQ }}$ (Figure $4 \mathrm{c}$ ). 
All $\gamma$ ' precipitates nucleated and grew during the cooling stage once the temperature passed below the $\gamma^{\prime}$ solvus, and possibly again during the following water quenching. The size of $\gamma^{\prime}$ precipitates observed in the recrystallized grains is indeed comparable to the size of the precipitates formed during quenching of sample $\mathrm{q}_{1125}$. Therefore those precipitates are denoted $\gamma^{\prime}{ }_{\text {wQ }}$ on Figure $4 \mathrm{c}$, and will be excluded from further analyses since they have not formed during the slow cooling.

The size of $\gamma^{\prime}{ }_{1075} \mathrm{NR}$ precipitates $(130 \mathrm{~nm})$ is significantly larger than that of $\gamma^{\prime}{ }_{\mathrm{WQ}}(\sim 20$ $\mathrm{nm})$. Precipitation is very likely to be promoted by the presence of a higher dislocation content in the unrecrystallized area compared to the recrystallized area. Indeed, dislocations can promote $\gamma^{\prime}$ precipitation as the result of both following phenomena: (1) dislocations lines can act as higher diffusivity paths for (Al, Ti) solute atoms [23] compared to the perfect crystal; (2) dislocation neighborhoods can act as sites allowing relaxation of elastic strain induced by the nucleation of $\gamma^{\prime}$ nuclei [24]. From the results presented below, another explanation should also be considered, where the recrystallization front would have dissolved precipitates previously formed while the recrystallized grains grew. 


\subsection{Analysis of the sample $q_{1000}$ quenched after slow cooling down to $1000{ }^{\circ} \mathrm{C}$}
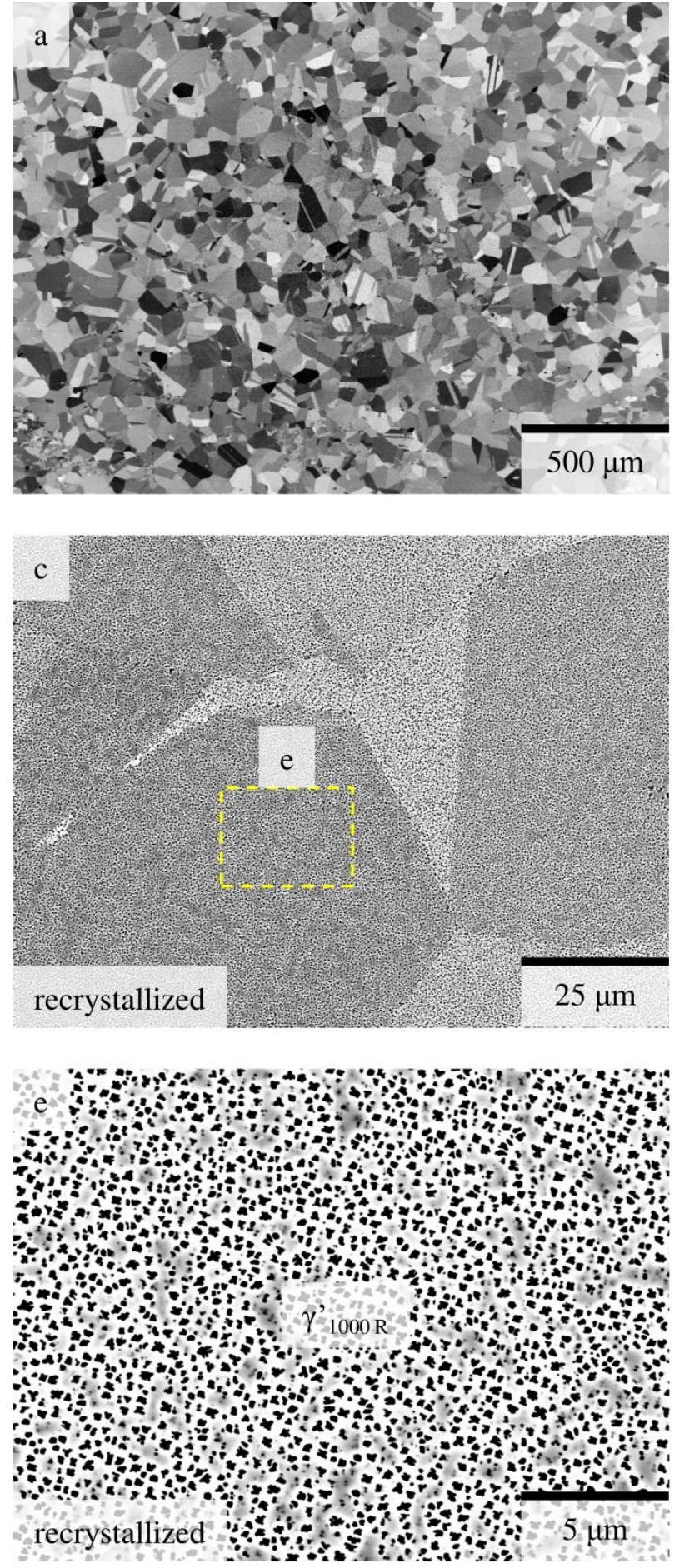
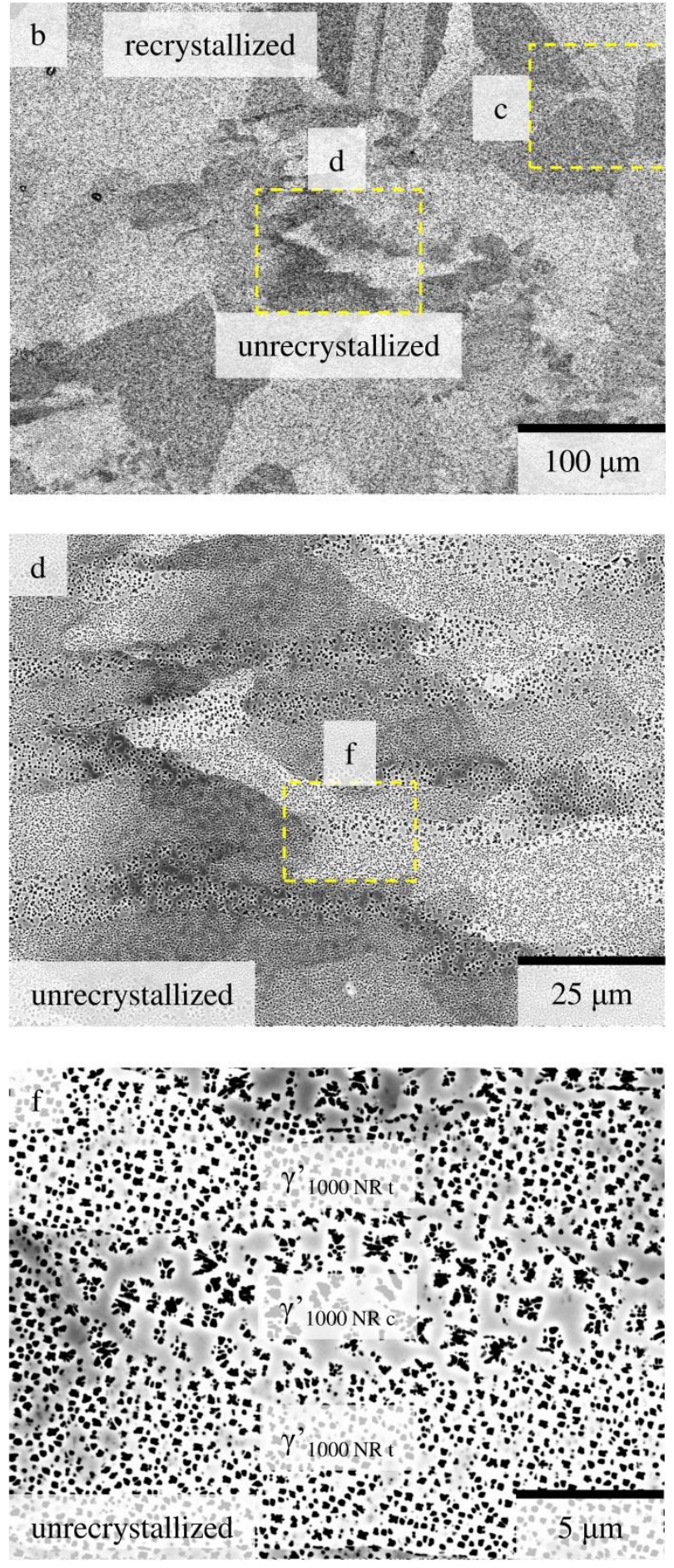

Figure 5: BSE images of the sample $\mathrm{q}_{1000}$ (the compression direction is vertical), showing (a) an overview of the microstructure, (b) recrystallized and unrecrystallized areas, 


$$
\text { (c, e) } \gamma^{\prime}{ }_{1000 \mathrm{R}} \text { in an recrystallized area, }
$$

$(\mathrm{d}, \mathrm{f})$ alternate horizontal arms/bands of $\gamma^{\prime} 1000 \mathrm{NR} \mathrm{t}$ and $\gamma^{\prime} 1000 \mathrm{NR} \mathrm{c}$ in an unrecrystallized area.
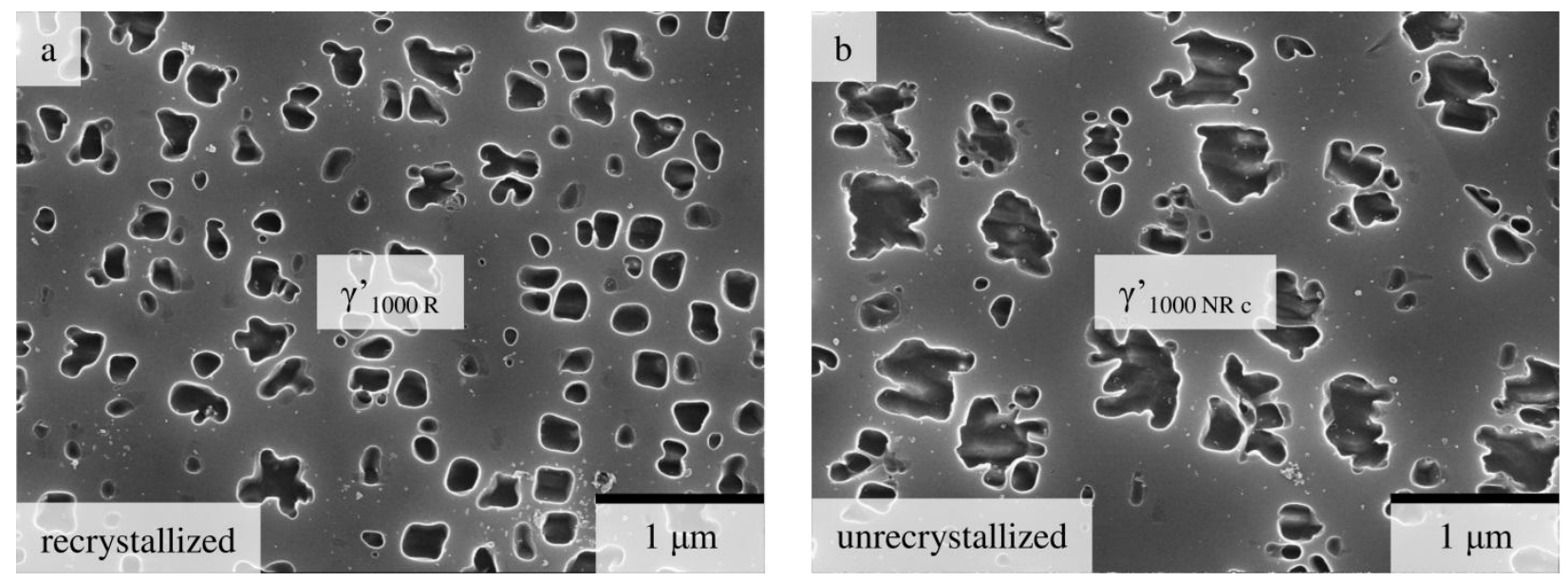

Figure 6: $\mathrm{SE}$ images of the sample $\mathrm{q}_{1000}$ (the compression direction is vertical) showing (a) $\gamma^{\prime} 1000 \mathrm{R}$ and (b) $\gamma^{\prime} 1000 \mathrm{NR}$ c precipitates in an unrecrystallized area.

Regarding recrystallization, Figure 5a shows that post-dynamic recrystallization has significantly progressed. The recrystallization fraction is now $91 \%$ and recrystallized grains are much larger ( $46 \mu \mathrm{m}$ mean equivalent diameter). Those large recrystallized grains have grown post-dynamically during slow cooling down to $1000^{\circ} \mathrm{C}$. Regarding $\gamma^{\prime}$ precipitation, horizontal (orthogonal to the compression axis) alternate bands of thin and coarse $\gamma^{\prime}$ precipitates are observed inside the unrecrystallized areas. Three $\gamma^{\prime}$ precipitation regions are defined:

(1) in the recrystallized area, $\gamma$ ' precipitates with $168 \mathrm{~nm}$ mean equivalent diameter are denoted as $\gamma^{\prime}{ }_{1000 \mathrm{R}}$ (Figure 5(c, e), Figure 6a),

(2) in the unrecrystallized area, , $\gamma^{\prime}$ precipitates with $168 \mathrm{~nm}$ mean equivalent diameter in some of the bands are denoted as $\gamma^{\prime}{ }_{1000 \mathrm{NR}} \mathrm{t}$ (Figure $5(\mathrm{~d}, \mathrm{f})$ ), where " $\mathrm{t}$ " stands for "thin", and are similar to the $\gamma^{\prime} 1000$ R precipitates, 
(3) in the unrecrystallized area, protruded $\gamma^{\prime}$ precipitates with $175 \mathrm{~nm}$ mean equivalent diameter in some of the bands are denoted as $\gamma^{\prime}{ }_{1000 \mathrm{NR} \text { c }}$ (Figure 5 (d, f), Figure 6b), where "c" stands for "coarse".

In the recrystallized area, the $\gamma^{\prime}{ }_{1000 \mathrm{R}}$ precipitates grew during the cooling from $1075^{\circ} \mathrm{C}$ down to $1000{ }^{\circ} \mathrm{C}$. In the unrecrystallized area, the $\gamma^{\prime}{ }_{1000 \mathrm{NR}}$ or $\gamma^{\prime}{ }_{1000 \mathrm{NR}} \mathrm{c}$ both result from the evolution of the $\gamma^{\prime} 1075$ NR precipitates. The differentiation may come from dislocation density fluctuations in the deformation structures developed orthogonally to the compression direction. The higher the dislocation density the faster the precipitate growth, as dislocations act as higher-diffusivity paths. The horizontal orientation of the precipitates bands is indeed consistent with the horizontal elongation of flattened intragranular structures in unrecrystallized grains of samples $\mathrm{q}_{1125}$ (Figure $2 \mathrm{~b}$ ) and $\mathrm{q}_{1075}$ (Figure $3 b$ ). This could nevertheless not be confirmed by analyzing the local misorientations in the two kinds of bands within EBSD maps. Local misorientations are associated with the density of geometrically necessary dislocations (GNDs). Thus, if the size of $\gamma^{\prime}$ precipitate is related to the local dislocation density, then the difference in dislocation density is below what EBSD is able to reveal, or a significant amount of statistically stored dislocations (SSDs, not accessible by EBSD) is involved in the deformation substructures. 


\subsection{Analysis of the sample $q_{400}$ cooled down to $400{ }^{\circ} \mathrm{C}$}
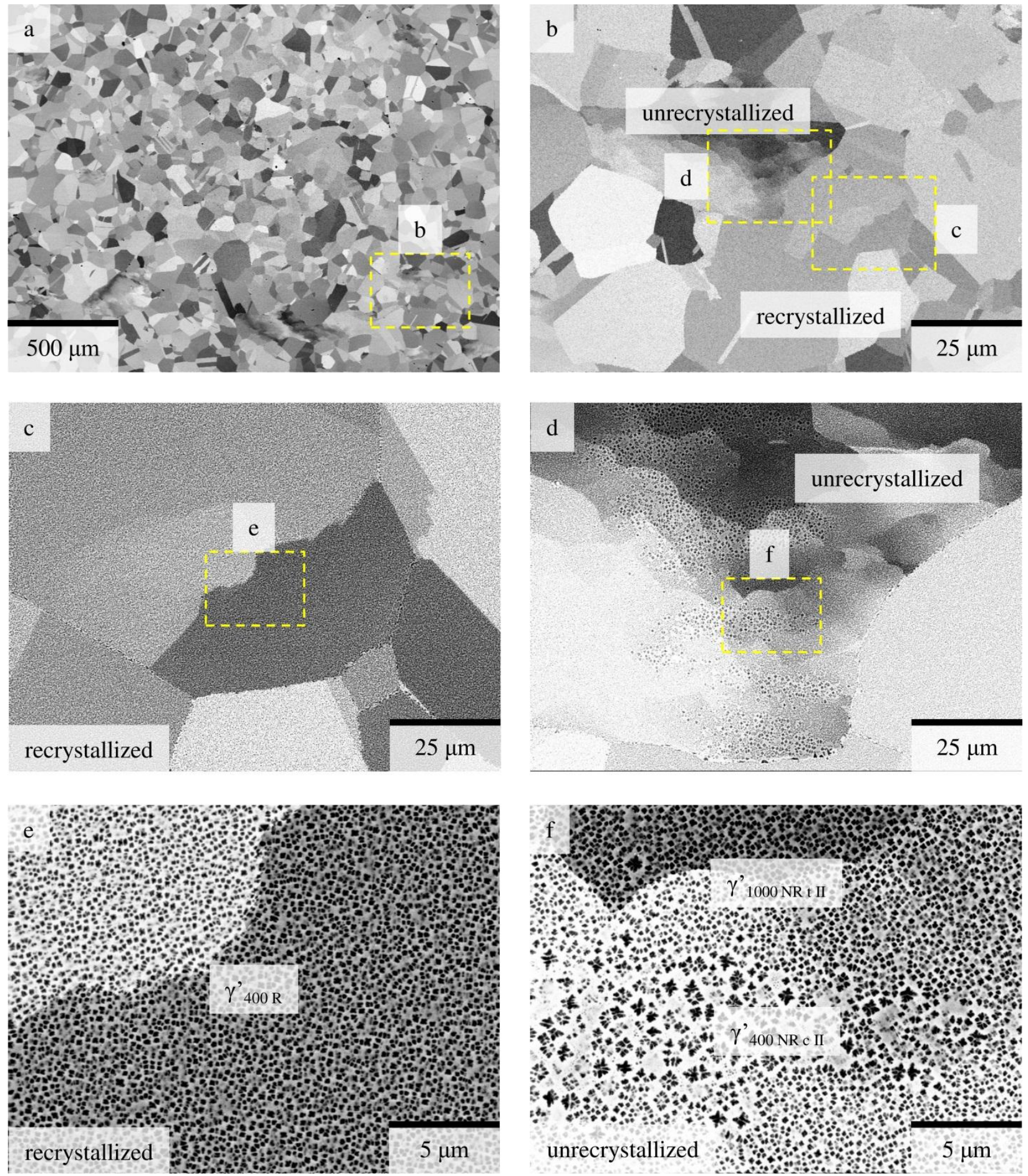

Figure 7: BSE images of the sample $\mathrm{q}_{400}$ (the compression direction is vertical), showing (a) an overview of the microstructure, (b) recrystallized and unrecrystallized areas, 
(c, e) $\gamma_{400 \mathrm{R}}$ precipitates in an recrystallized area,

$(\mathrm{d}, \mathrm{f})$ alternate horizontal arms/bands of $\gamma^{\prime} 400 \mathrm{NR}$ t and $\gamma^{\prime}{ }_{400 \mathrm{NR} \mathrm{c}}$ in an unrecrystallized area.
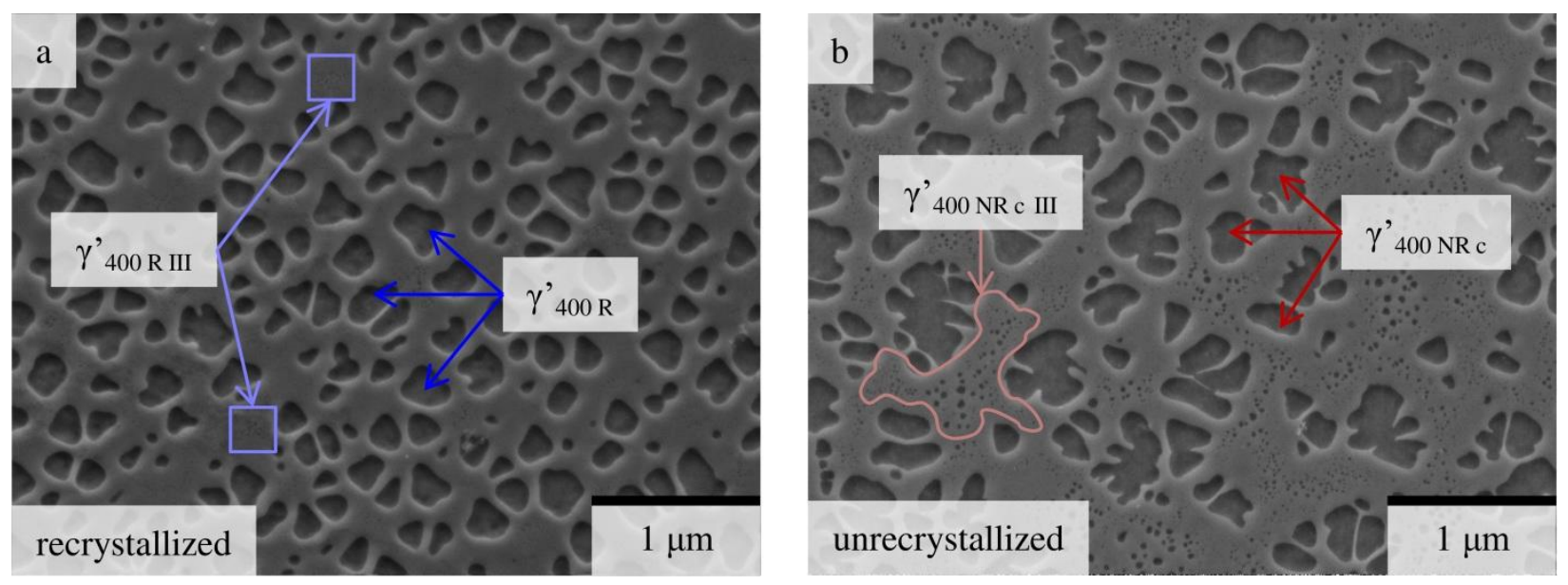

Figure 8: SE images of the sample $\mathrm{q}_{400}$ (the compression direction is vertical) showing (a) $\gamma^{\prime} 400 \mathrm{R}, \gamma^{\prime}{ }_{400 \mathrm{R} \mathrm{III}}$ in a recrystallized area,

(b) $\gamma_{400 \mathrm{NR} c}$ and $\gamma_{400 \mathrm{NR} \text { c III }}$ precipitates in an unrecrystallized area.
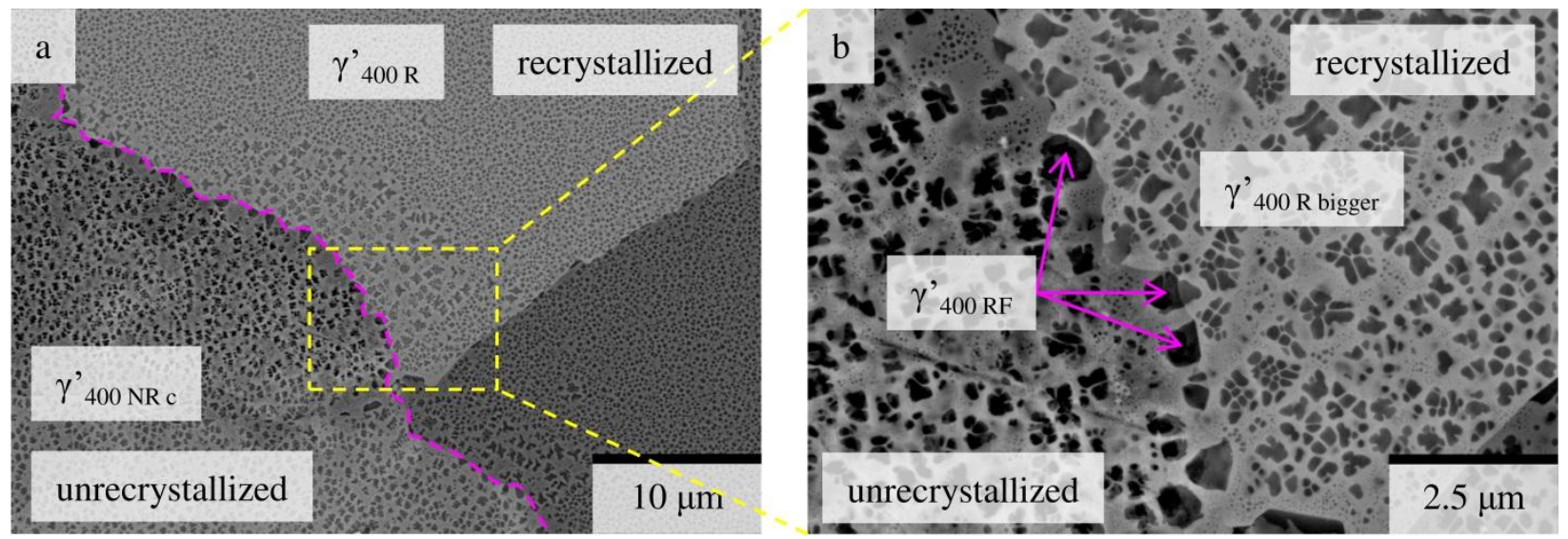

Figure 9: BSE images of the sample $\mathrm{q}_{400}$ (the compression direction is vertical) showing (a) $\gamma^{\prime}{ }_{400 \mathrm{R}}$ and $\gamma^{\prime}{ }_{400 \mathrm{NR}} \mathrm{c}$ precipitates on both sides of the recrystallization front (dashed magenta curve) and (b) $\gamma^{\prime}{ }_{400 \mathrm{RF}}$ precipitates on the recrystallization front and $\gamma^{\prime} 400 \mathrm{R}$ bigger precipitates near the recrystallized front in the recrystallized area.

In the sample slow cooled down to $400^{\circ} \mathrm{C}$, the recrystallized fraction (Figure 7a) is $93 \%$, comparable to the one at $1000{ }^{\circ} \mathrm{C}$ (Figure 5a), and recrystallized grains are bigger (63 
$\mu \mathrm{m}$ ). Those large recrystallized grains thus kept growing between $1000{ }^{\circ} \mathrm{C}$ (Figure 5a) and $400{ }^{\circ} \mathrm{C}$ (Figure 7a) but to a lower extent compared to how much they grew from 1075 to $1000{ }^{\circ} \mathrm{C}$. This drop in growth rate of recrystallized grains comes from the lower temperature and the decrease in stored energy due to the progression of recrystallization. However, there are still few unrecrystallized areas (Figure 7b), where alternate bands of fine and coarser $\gamma$ ' precipitates, similar to those observed in the sample $\mathrm{q}_{1000}$ can still be found (Figure 7(d, f)). Regarding $\gamma$ ' precipitates, eight regions are defined :

(1) in the recrystallized area, secondary $\gamma$ ' precipitates with $160 \mathrm{~nm}$ mean equivalent diameter are denoted $\gamma^{\prime} 400 \mathrm{R}$ (Figure 7(c, e), Figure 8a),

(2) in the recrystallized area, in between the former ones (which are actually secondary precipitates according to the classical terminology), much smaller $\gamma^{\prime}$ precipitates have appeared during the cooling from $1000{ }^{\circ} \mathrm{C}$ to $400{ }^{\circ} \mathrm{C}$ and are denoted $\gamma^{\prime} 400 \mathrm{R} \mathrm{III}$ (Figure 8a) as they are tertiary $\gamma^{\prime}$ precipitates (following the same classical terminology),

(3) in the fine precipitates bands of unrecrystallized areas, $\gamma^{\prime}$ precipitates with $160 \mathrm{~nm}$ mean equivalent diameter are denoted $\gamma^{\prime} 400 \mathrm{NR}$ t (Figure 7(d, f)),

(4) in the fine precipitates bands of unrecrystallized areas, tertiary $\gamma^{\prime}$ precipitates are

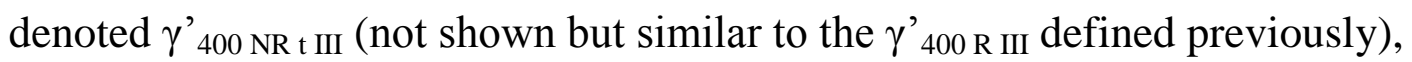

(5) in the coarse precipitates bands of unrecrystallized areas, secondary $\gamma^{\prime}$ precipitates with $212 \mathrm{~nm}$ mean equivalent diameter are denoted $\gamma^{\prime}{ }_{400 \mathrm{NR} \text { c }}$ (Figure 7(d, f), Figure $8 b)$,

(6) in the coarse precipitates bands of unrecrystallized areas, tertiary $\gamma^{\prime}$ precipitates are denoted $\gamma^{\prime} 400$ NR c III (Figure 8b),

(7) on the recrystallization front (dashed magenta curve in Figure 14), $750 \mathrm{~nm} \gamma^{\prime}$ precipitates are denoted $\gamma_{400 \mathrm{RF}}^{\prime}$ (Figure 14),

(8) in the recrystallized area, in a limited region near the recrystallization front, $\gamma$ ' precipitates with a size similar to that of $\gamma^{\prime} 400 \mathrm{RF}$ precipitates but with a different morphology are present and denoted as $\gamma^{\prime} 400 \mathrm{R}$, bigger (Figure 14). 
The very fine precipitates formed during cooling from $1000^{\circ} \mathrm{C}$ to $400^{\circ} \mathrm{C}$ are tertiary precipitates, all others fall into the category of secondary precipitates, with regards to the fact they formed at higher temperatures and have larger sizes. Secondary and tertiary precipitates have been separated on a mean equivalent diameter criterion based on digital images processing measurements done on SE images like those of Figure 9. The thresholds used are $40 \mathrm{~nm}$ for $\gamma_{400 \mathrm{R}}^{\prime} / \gamma^{\prime}{ }_{400 \mathrm{R} \mathrm{III}}$ and $\gamma^{\prime}{ }_{400 \mathrm{NR}} \mathrm{t} \gamma^{\prime}{ }_{400 \mathrm{NR}} \mathrm{tIII}$ and $80 \mathrm{~nm}$ for the $\gamma^{\prime} 400 \mathrm{NR} c \gamma^{\prime} 400 \mathrm{NR}$ c III. These thresholds are indicated on the equivalent diameters distributions of $\gamma^{\prime}$ precipitates in Figure 14(d, e).

The origin of these eight $\gamma^{\prime}$ precipitates populations can be explained as follows. In the recrystallized area, the secondary $\gamma^{\prime} 400 \mathrm{R}$ precipitates result from the evolution of $\gamma^{\prime} 1000 \mathrm{R}$ precipitates. The tertiary $\gamma^{\prime}{ }_{400 \mathrm{R} \mathrm{III}}$ appeared during cooling from $1000{ }^{\circ} \mathrm{C}$ to $400{ }^{\circ} \mathrm{C}$, according to a very well-known process. As temperature goes down, the $\gamma^{\prime}$ equilibrium volume fraction should increase steadily [25], but at some point, diffusion is no longer fast enough to make secondary precipitates keep growing. The matrix gets supersaturated, which gives rise to the nucleation of very fine tertiary precipitates in between former secondary ones. Similarly, in the unrecrystallized area, the secondary $\gamma^{\prime}{ }_{400 \mathrm{NR}} \mathrm{t}$ and $\gamma^{\prime}{ }_{400 \mathrm{NR}}$ c come from the $\gamma^{\prime}{ }_{1000 \mathrm{NR} t}$ and $\gamma^{\prime}{ }_{1000 \mathrm{NR}}{ }_{\mathrm{c}}$ respectively and tertiary $\gamma^{\prime}{ }_{400 \mathrm{NR} \text { t III }}$ and $\gamma^{\prime}{ }_{400 \mathrm{NR} \text { c III }}$ precipitates formed in between during the cooling from $1000{ }^{\circ} \mathrm{C}$ to $400{ }^{\circ} \mathrm{C}$.

The $\gamma_{400 \mathrm{RF}}$ precipitates observed on the recrystallization front are rather large and have more compact shapes compared to the other $\gamma$ ' precipitates of the sample $\mathrm{q}_{400}$. This can result from a hastened growth of the $\gamma^{\prime}{ }_{1000 \mathrm{NR}}$ and/or $\gamma^{\prime}{ }_{1000 \mathrm{NR}} \mathrm{c}$ precipitates, triggered by the recrystallization front. Indeed, when it meets them by migrating from the recrystallized area towards the unrecrystallized area, it can act as a high-diffusivity path and/or (Al, Ti) solute segregation site promoting the growth of the encountered $\gamma^{\prime}{ }_{1000 \mathrm{NR}} \mathrm{t}$ $\gamma^{\prime}{ }_{1000 \mathrm{NR} \text { c }}$ precipitates.

Eventually, the $\gamma^{\prime}{ }_{400 \mathrm{R} \text { bigger }}$ precipitates may be related to the near and similarly sized $\gamma^{\prime}{ }_{400}$ RF precipitates on the recrystallization front. This can be explained by a hastened growth 
promoted by a faster diffusion along the recrystallization front. When the recrystallization front migrates and meets $\gamma^{\prime}$ precipitates of the unrecrystallized areas, the recrystallization front is slowed down by the Smith-Zener pinning effect. Then diffusive processes have time to proceed. From our observations, it seems that the recrystallization dissolves preexisting $\gamma^{\prime}$ precipitates and form new bigger ones or that some of the former ones coarsen to the detriment of smaller ones. Eventually such diffusive processes lead to the big and compact shaped precipitates denoted $\gamma^{\prime}{ }_{400 \mathrm{RF}}$. The last type of observed precipitates, denoted $\gamma^{\prime}{ }_{400 \mathrm{R} \text { bigger, }}$, have similar sizes compared to the former ones, but different shapes. Further observations, shown below, might provide hints into their formation mechanisms and how they could be related to $\gamma_{400 \mathrm{RF}}$ precipitates.
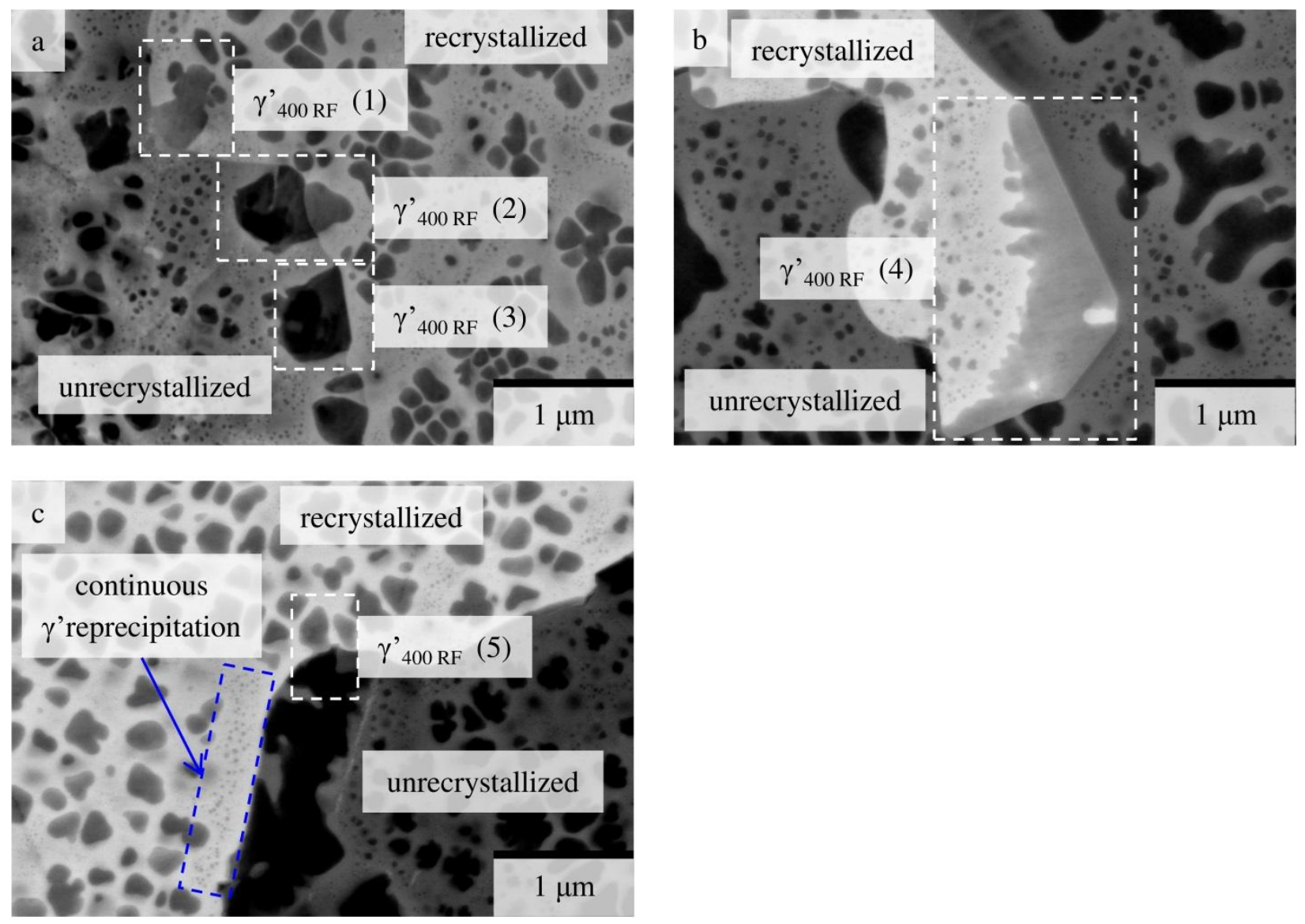

Figure 10: BSE images in the sample $\mathrm{q}_{400}$ along on the recrystallization front, showing both recrystallized (bright) and unrecrystallized (dark) areas and $\gamma^{\prime}{ }_{400 \mathrm{RF}}$ precipitates on the recrystallization front: (a) 3 localizations of the $\gamma^{\prime}$ phase 
((1) in the recrystallized area, (2) in both recrystallized and unrecrystallized areas, (3) in the unrecrystallized area); (b) $\gamma^{\prime} 400$ RF precipitate in the recrystallized area; (c) $\gamma^{\prime}$ localization in both recrystallized and unrecrystallized areas where (5) is the part in the recrystallized area, and scattered thinner $\gamma$ ' precipitates in the recrystallized area (blue rectangle).

Figure 10 focuses on the precipitates $\gamma^{\prime}{ }_{400 \mathrm{RF}}$ observed on the recrystallization front to study the recrystallization front/precipitation interaction. All these precipitates are bigger than the ones in the unrecrystallized area. This is attributed to the enhanced ( $\mathrm{Al}, \mathrm{Ti})$ solute diffusion favored by the recrystallization front as a grain boundary when meeting the precipitates, thus promoting their growth. The most striking case is in Figure 10b where the position and morphology of $\gamma^{\prime}$ precipitate (4), stuck to the recrystallization front, indicates that it benefitted from a hastened diffusion and then a growth oriented along the recrystallization front. Different morphologies and positions of the $\gamma^{\prime}{ }_{400 \mathrm{RF}}$ precipitates in Figure 10 suggest the following physical mechanisms. The $\gamma_{400 \mathrm{RF}}^{\prime}$ precipitates (1) and (4) seem to have reprecipitated discontinuously in the recrystallized front side, i.e. behind the recrystallization front. This could proceed by first the complete dissolution of a $\gamma^{\prime}$ precipitate previously existing in the unrecrystallized side which would have led to (Al, Ti) solute supersaturation, and then would have stimulated the re-precipitation on the recrystallized side as the front migrated. The $\gamma^{\prime}{ }_{400 \mathrm{RF}}$ precipitates (2) and (5) could have formed by a similar process. They seem being dissolved by the recrystallization front, and to have discontinuously reprecipitating behind it, in the recrystallized side once again due to the (Al, Ti) solute supersaturated matrix. Hence $\gamma^{\prime} 400 \mathrm{RF}$ precipitates (2) and (5) would arise from a similar mechanism as $\gamma^{\prime}{ }_{400 \mathrm{RF}}$ precipitate (1) but be seen at an earlier time i.e. during the dissolution by the migrating recrystallization front rather than after. The $\gamma^{\prime} 400$ ${ }_{\mathrm{RF}}$ precipitates (2) and (5) could also be cut by the recrystallization front with the creation of a boundary inside the $\gamma^{\prime}$ precipitates preserving the coherency $\gamma / \gamma^{\prime}$ phase interface, as already reported in Ni-based superalloys [26, 27]. Discontinuous reprecipitation behind the recrystallization front has already been observed in Ni-base superalloys [28]. 
Moreover, grain boundary migration during creep tests was reported in [29] to be accompanied by discontinuous coarsening of $\gamma^{\prime}$ rods, as the grain boundary moved from high dislocation content areas towards lower dislocation content areas. Eventually, the $\gamma^{\prime}$ precipitate (3) seems to be, like $\gamma^{\prime}{ }_{400 \mathrm{RF}}$ precipitates (2) and (5) being dissolved by the recrystallization front migrating from right to left, but no discontinuous reprecipitation occured behind the recrystallization fronts. This means that the (Al, Ti) solute locally supersaturates the matrix in the recrystallized side. This could later (i.e. at lower temperature in our cooling experiments) trigger continuous reprecipitation. Such continuous reprecipitation leads to thin and regularly spaced $\gamma^{\prime}$ precipitates (blue rectangle in Figure 10). To summarize, recrystallization front dissolves the $\gamma^{\prime}$ precipitates of the consumed unrecrystallized grain. Then, the local (Al, Ti) solute supersaturation in the recrystallized side of the matrix may trigger discontinuous $\gamma^{\prime}$ reprecipitation ((1), (2), (4) and (5); Figure 10). Continuous $\gamma$ ' reprecipitation appears to be possible also (Figure $10 \mathrm{c})$. 

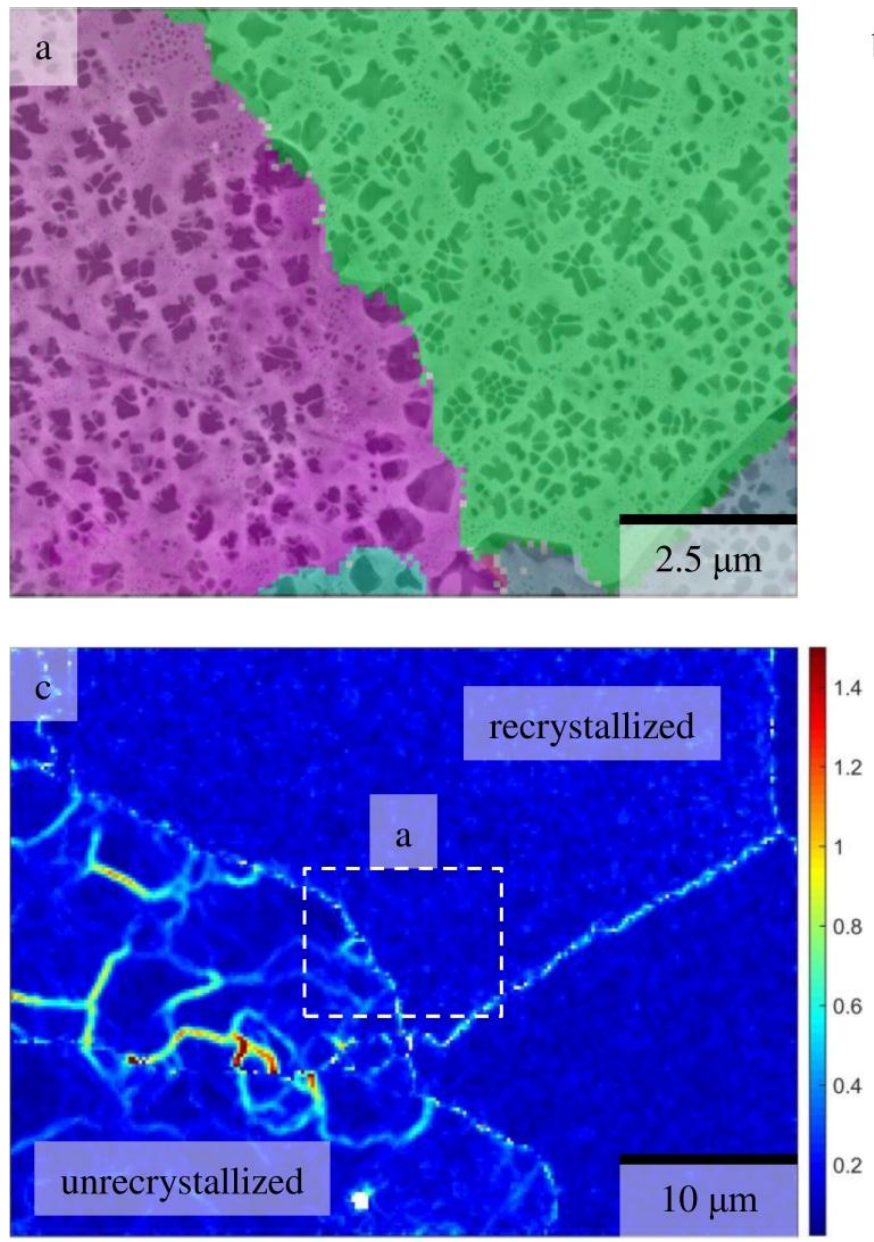

Figure 11: in sample $\mathrm{q}_{400}$, (a) corresponding crystallographic orientation maps on top of

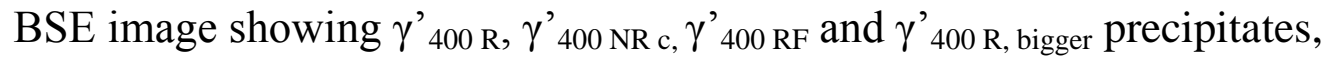

(b) definition of the inverse pole figure,

color-coding is relative to the (vertical) compression direction

(c) KAM map in degree of the same area unmagnified 4 times (matches Figure 9a).

Figure 11 shows an EBSD map of an area covering both sides of a recrystallization front. At the bottom right corner of Figure 11a, the slight shift of the grain boundary between the BSE image and the overlaid crystallographic orientation map on the grain boundary comes from experimental distortion of the EBSD scan, but does not prevent from analyzing interesting pieces of information. The kernel average misorientation (KAM) map (Figure 11c) has been calculated after processing the crystallographic orientation 
EBSD map to reduce the experimental orientation noise while preserving the actual misorientations structures, using a newly developed filter [30]. This KAM map clearly reveals intragranular misorientations and recovery sub-boundaries in the unrecrystallized area. On the contrary, the recrystallized grains have very homogeneous orientations, as they do not contain many dislocations. All $\gamma^{\prime}$ precipitates have the same crystallographic orientation as their surrounding $\gamma$ matrix. For the unrecrystallized area, this means that all $\gamma^{\prime}$ precipitates grew with a coherent interface from their nucleation. For the recrystallized area, it means that each $\gamma^{\prime}$ precipitate may have two possible histories. Either it nucleated and grew coherently in a pre-existing recrystallized grain or it re-precipitated (continuously or discontinuously, Figure 10) coherently on the recrystallized side behind a recrystallization front that dissolved pre-existing $\gamma^{\prime}$ precipitates. Continuous and discontinuous coherent re-precipitation processes are consistent with the results on another Ni-based superalloy reported in [28].

Eventually, as the discontinuously re-precipitated $\gamma^{\prime}$ precipitates (Figure 10, $\gamma^{\prime}{ }_{400 \mathrm{RF}}$ types (1) and (2)) are bigger than the $\gamma^{\prime}{ }_{400 \mathrm{R}}$ inside the recrystallized area, they subsequently become the so-called $\gamma^{\prime} 400 \mathrm{R}$ bigger precipitates (Figure $9 \mathrm{~b}$ ) after being bypassed by the recrystallization front. Such $\gamma^{\prime}{ }_{400} \mathrm{R}$ bigger indeed seem to subdivide, as coherent $\gamma^{\prime}$ precipitates usually do to reduce their overall thermodynamic potential, balancing the contribution of the volumic elastic strain and of the coherent $\gamma / \gamma^{\prime}$ interfacial energy [31, 32].

\section{Post-dynamic recrystallization and precipitation as concomitant mechanisms.}

Quantitative data obtained from the microstructure analyses presented in section 2 are summarized in Figure 12 regarding the progression of recrystallization, in Figure 14 and Figure 15 regarding the evolution of $\gamma^{\prime}$ precipitates. 


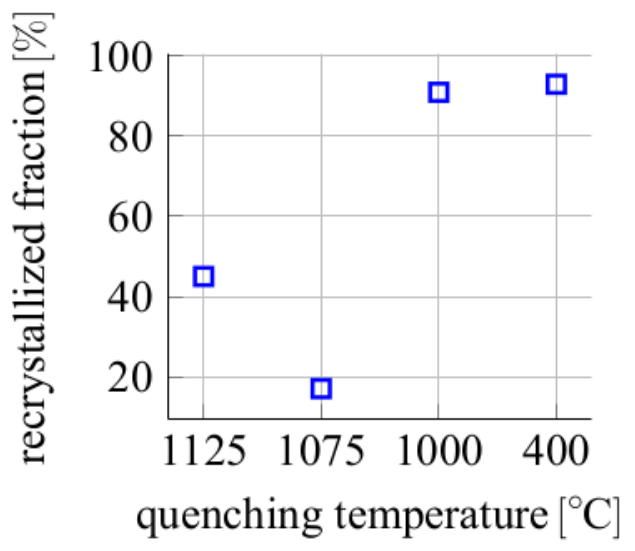

(a)

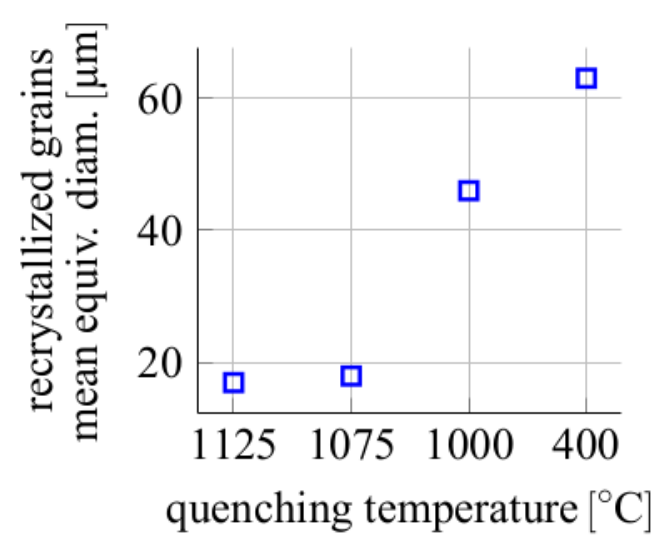

(b)

Figure 12: (a) recrystallized volume fraction and (b) mean recrystallized grain size as a function of quenching temperature.

As commented previously, the different $\gamma^{\prime}$ precipitates populations are assumed to represent the evolution at successive quenching temperatures of the same type of $\gamma^{\prime}$ precipitates. As a consequence, the nomenclature of all $\gamma^{\prime}$ precipitates populations can be simplified (Figure 13) by dropping the temperature subscript and merging together the $\gamma^{\prime}$ precipitates types when they present the same defining characteristics (localization in the recrystallized or unrecrystallization, thin or coarse size), and probably represent, at different quenching temperatures, the evolution along cooling of a same $\gamma^{\prime}$ precipitate population.

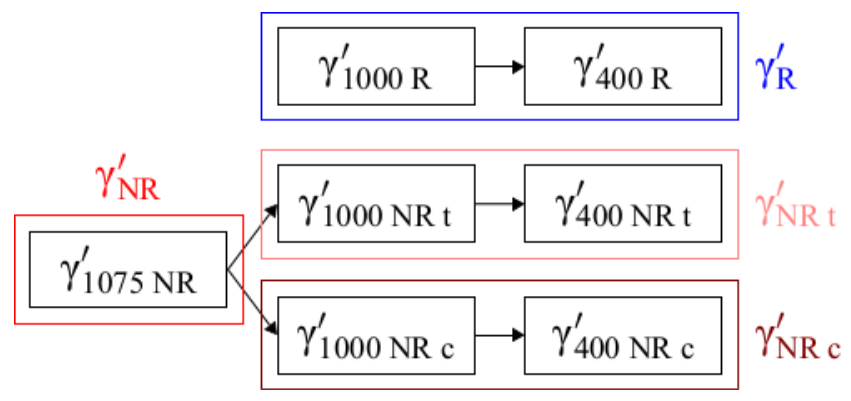

Figure 13: simplified nomenclature of $\gamma^{\prime}$ precipitate types. 
As explained in section 2.2, the greater recrystallization fraction in $\mathrm{q}_{1125}$ compared to $\mathrm{q}_{1075}$ can only be explained by experimental variations from sample to sample, notably on the temperature and the displacement. Consequently, recrystallized fractions of samples $\mathrm{q}_{1125}$ and $\mathrm{q}_{1075}$ will not be compared, but it is clear from Figure 12a that those two values associated with high temperature states are significantly lower than those of samples $\mathrm{q}_{1000}$ and $\mathrm{q}_{400}$. Post dynamic recrystallization induces drastic changes in the grain structure of the alloy while cooling down to $1000^{\circ} \mathrm{C}$ (Figure 5(a, b)), and then the recrystallized grain size keeps increasing between $1000{ }^{\circ} \mathrm{C}$ and $400{ }^{\circ} \mathrm{C}$. Since post-dynamic recrystallization is almost already completed at $1000{ }^{\circ} \mathrm{C}$, the subsequent increase in grain size is probably more driven by capillarity forces acting on grain boundaries than by stored energy consumption. 
recrystallized

$\square \gamma_{\mathrm{R}}^{\prime}$
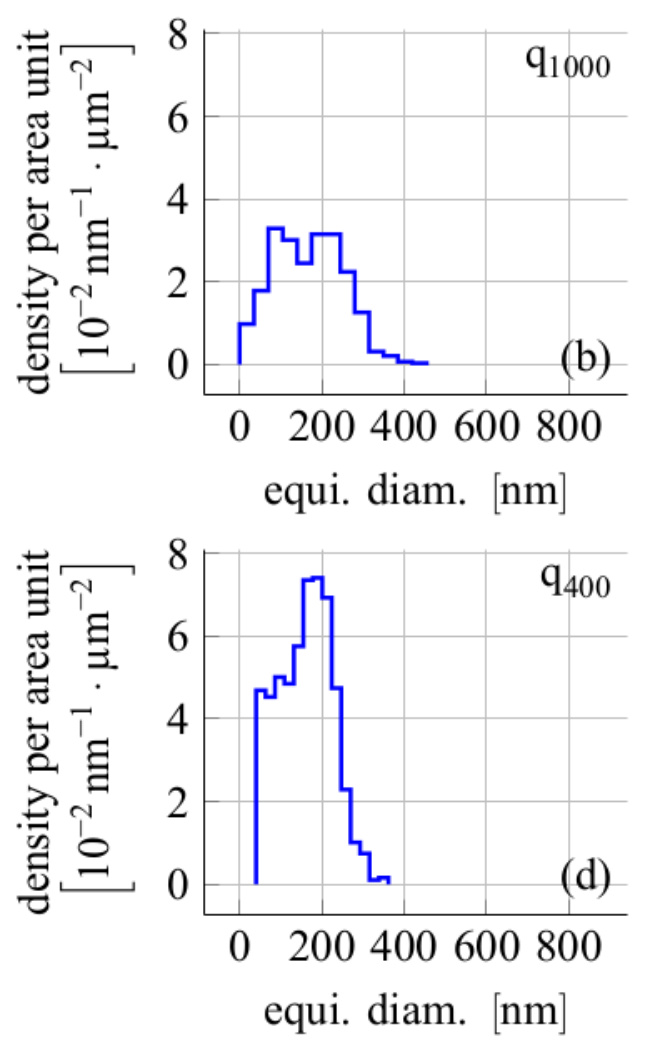

unrecrystallized

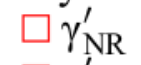

$\square \gamma_{\mathrm{NR} \mathrm{t}}^{\prime}$

$\square \gamma_{\mathrm{NR} \mathrm{c}}^{\prime}$
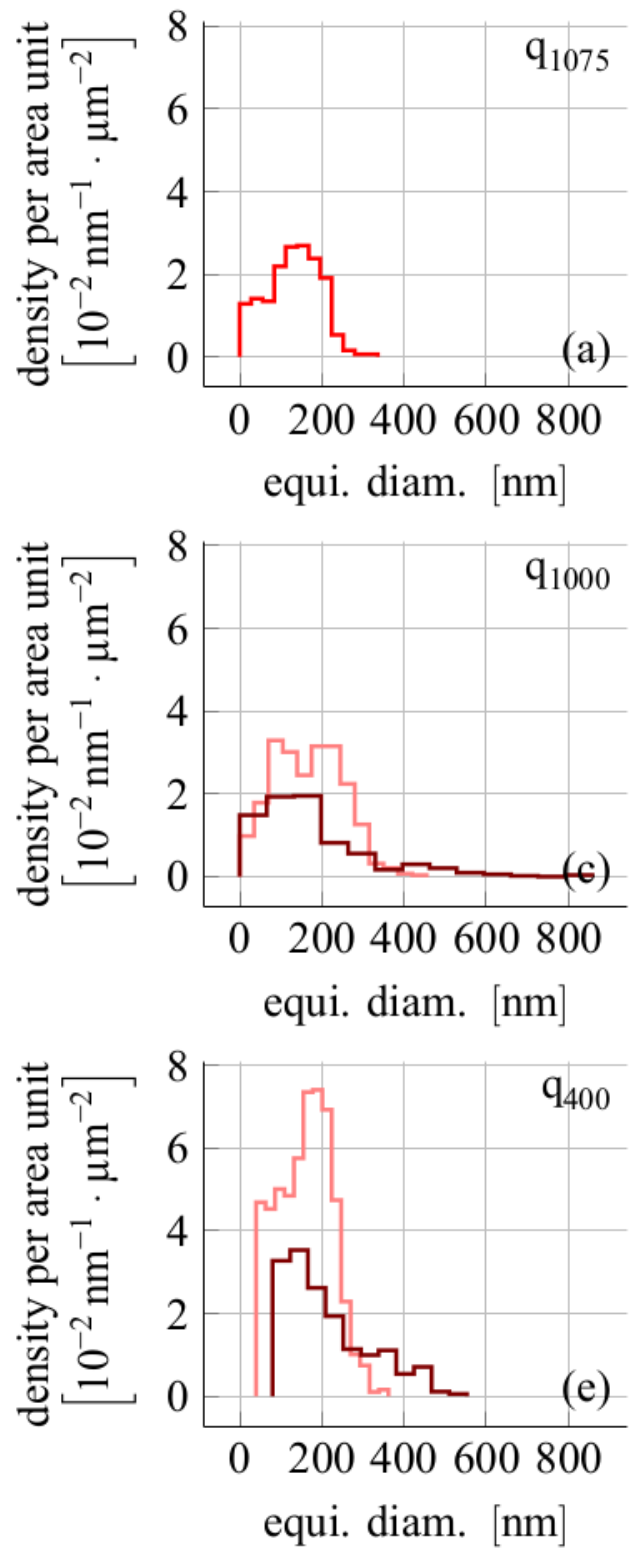

Figure 14: Density histograms (bin width from Scott rule [33]) of equivalent diameter of $\gamma^{\prime} 400 \mathrm{R}$ and $\gamma^{\prime}{ }_{400 \mathrm{NR}}$ per area unit of the different $\gamma^{\prime}$ precipitates populations, rows correspond to quenching temperatures (a) $1075{ }^{\circ} \mathrm{C}$, (b, c) $1000{ }^{\circ} \mathrm{C}$ and (d, e) $400{ }^{\circ} \mathrm{C}$. In (e) the leftmost bar of $\gamma^{\prime} 400 \mathrm{NR}$ c III distribution goes above $40 \mu \mathrm{m}^{-2}$ so it is cut at $5 \mu \mathrm{m}^{-2}$ to keep $\gamma^{\prime}{ }_{400 \mathrm{NR}} \mathrm{t}, \gamma^{\prime} 400 \mathrm{NR}$ t III and $\gamma^{\prime} 400 \mathrm{NR}$ c distributions visible. 
recrystallized

$$
\square \gamma_{\mathrm{R}}^{\prime}
$$

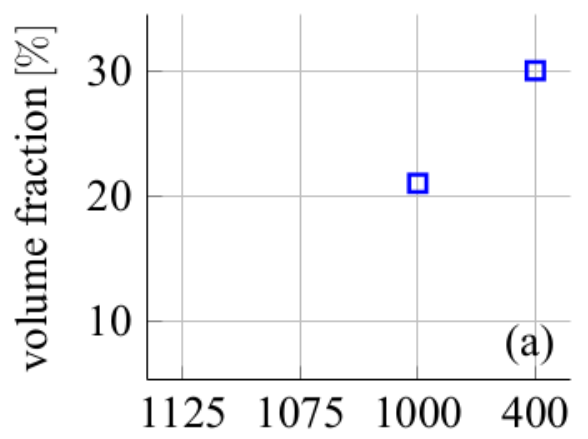

quenching temperature $\left[{ }^{\circ} \mathrm{C}\right]$

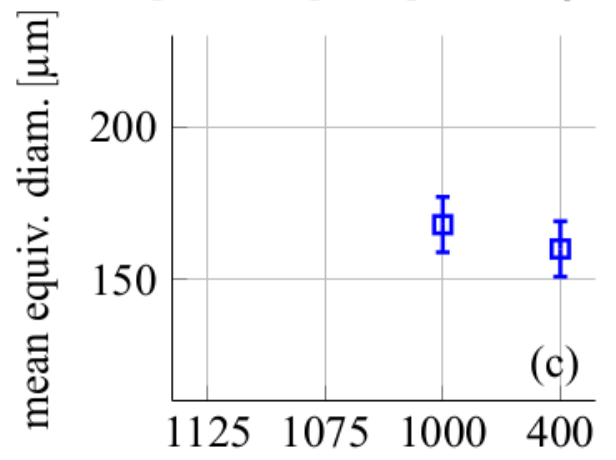

$\sim \quad$ quenching temperature $\left[{ }^{\circ} \mathrm{C}\right]$

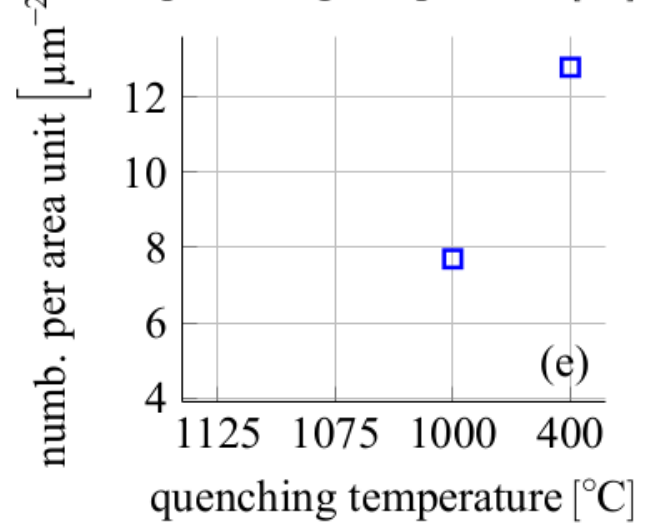

unrecrystallized

$\square \gamma_{\mathrm{NR}}^{\prime}$

$\square \gamma_{\mathrm{NR} \mathrm{t}}^{\prime}$

$\gamma_{\mathrm{NR} \mathrm{c}}^{\prime}$

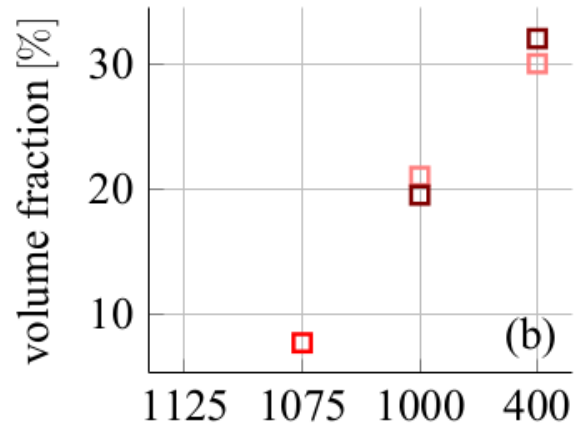

quenching temperature $\left[{ }^{\circ} \mathrm{C}\right]$

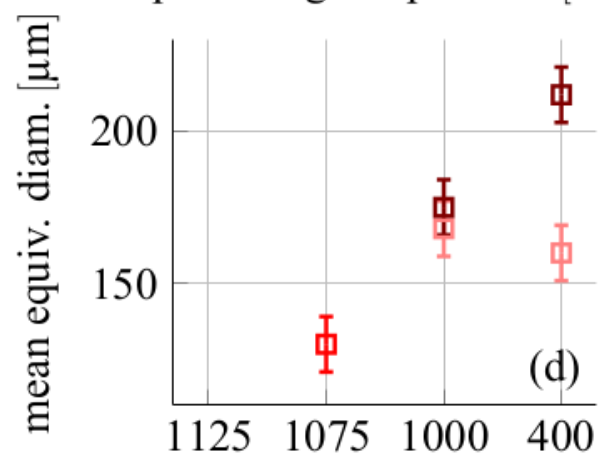

$\sim$ quenching temperature $\left[{ }^{\circ} \mathrm{C}\right]$

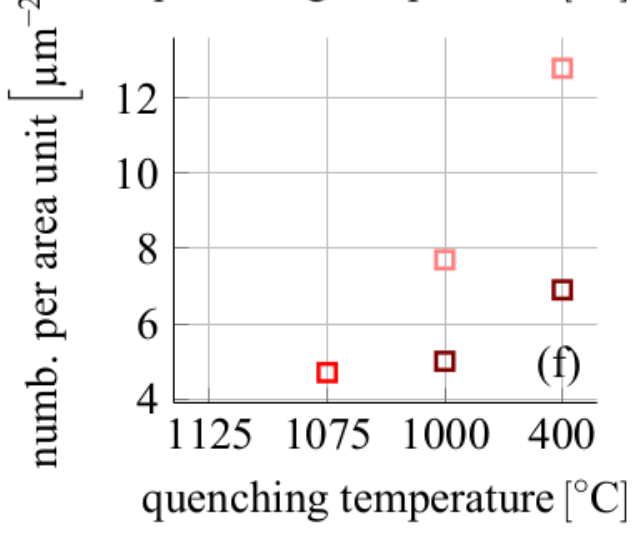

Figure 15: $\gamma^{\prime}$ volume fraction in the (a) recrystallized and (b) unrecrystallized areas, mean equivalent diameter of $\gamma^{\prime}$ precipitates in the (c) recrystallized and (d) unrecrystallized areas,

number of $\gamma^{\prime}$ precipitates per unit area in the (e) recrystallized and (f) unrecrystallized areas as a function of quenching temperature. 
The slow cooling $\gamma^{\prime}$ precipitation is first observed after quenching at $1075{ }^{\circ} \mathrm{C}$. In this sample, only what occurs in the unrecrystallized area ( $\gamma^{\prime}{ }_{1075 \text { NR }}$ precipitates) (Figure $3 d$, Figure 4b, Figure 14a, Figure 15(b, d, f)) should be considered to describe the evolutions upon slow-cooling. The $\gamma^{\prime}$ precipitates of the recrystallized area of sample $\mathrm{q}_{1075}$ (Figure 4c) are indeed likely to be formed during quenching. This difference in $\gamma$ ' precipitation between the unrecrystallized and recrystallized areas can be understood considering the higher dislocation content of the unrecrystallized area compared to that of the recrystallized grains. Dislocations lines may act as high-diffusivity roads for ( $\mathrm{Al}, \mathrm{Ti}$ ) solute atoms to feed the $\gamma^{\prime}$ precipitation and thus promote nucleation, growth and coarsening of $\gamma^{\prime}$ precipitates. An alternative explanation would be that pre-existing precipitates (nucleated in the deformed matrix) would have been dissolved into the recrystallization front as the recrystallized grains grew.

After cooling down to $1000{ }^{\circ} \mathrm{C}, \gamma^{\prime} 1000 \mathrm{R}$ precipitates appeared in the recrystallized area (Figure 5(c, e), Figure 6a, Figure 14b, Figure 15(a, c, e)) whereas in the unrecrystallized area, the $\gamma^{\prime}{ }_{1075 \mathrm{NR}}$ precipitates evolved to become either $\gamma^{\prime}{ }_{1000 \mathrm{NR} t}$ or $\gamma^{\prime} 1000 \mathrm{NR}$ c precipitates

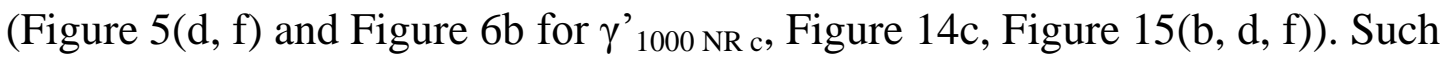
heterogeneity within the unrecrystallized area develops along "horizontal" bands/arms, orthogonal to the compression direction. A possible explanation could be a higher dislocation content in the regions where bigger precipitates $\left(\gamma^{\prime} 1000 \mathrm{c} \mathrm{NR}\right)$ are observed. The band orientation is indeed consistent with that of the flattened substructures of the unrecrystallized grains in samples $\mathrm{q}_{1125}$ (Figure $2 \mathrm{~b}$ ) and $\mathrm{q}_{1075}$ (Figure $3 \mathrm{~b}$ ). However, this explanation still remains to be validated in future works since no such dislocation density heterogeneity could not be assessed by simple EBSD data processing. The mean equivalent diameter distributions of $\gamma^{\prime}{ }_{1000 \mathrm{R}}, \gamma^{\prime}{ }_{1000 \mathrm{NR}}$ and $\gamma^{\prime} 1000 \mathrm{NR} \mathrm{c}$ (Figure 14(b, c)) show that the biggest $\gamma^{\prime}{ }_{1000 \mathrm{NR}}$ precipitates are larger than the biggest $\gamma^{\prime}{ }_{1000 \mathrm{R}}$ and $\gamma^{\prime}{ }_{1000 \mathrm{NR} \mathrm{t}}$ ones. However, the volume fraction are comparable: $21 \%$ for $\gamma^{\prime}{ }_{1000 \mathrm{R}}$ and $\gamma^{\prime}{ }_{1000 \mathrm{NR}}, 19.5$

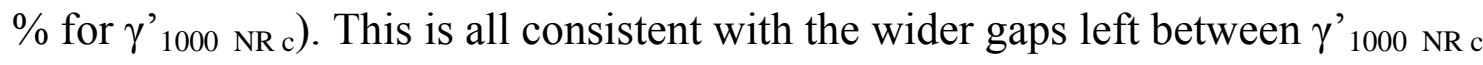
precipitates compared to the $\gamma^{\prime} 1000 \mathrm{~N}$ and $\gamma^{\prime} 1000 \mathrm{NR}$ ones, which compensate the bigger 
maximal sizes for a given volume fraction. Both are close to the $19 \%$ equilibrium $\gamma^{\prime}$ volume fraction calculated by ThermoCalc [25]. Consequently, it can be assumed that all three $\gamma^{\prime}$ precipitates populations are undergoing Ostwald ripening i.e. coarsening of the biggest $\gamma^{\prime}$ precipitates and shrinking up to dissolution of the smallest $\gamma^{\prime}$ precipitates at constant $\gamma^{\prime}$ volume fraction. Since the Ostwald ripening is directly accelerated by an

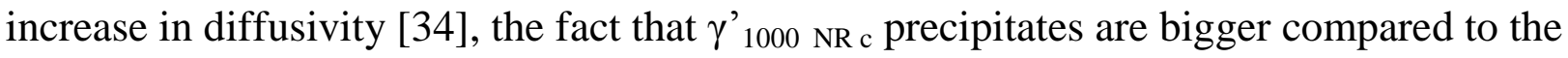
$\gamma^{\prime}{ }_{1000 \mathrm{R}}$ and $\gamma^{\prime}{ }_{1000 \mathrm{NR}}$ t precipitates could be attributed to a hastened diffusion promoted by dislocations lines in the region of the coarser $\gamma^{\prime}{ }_{1000} \mathrm{NR}$ c precipitates. This explains that in the distributions of mean equivalent diameters, the tail of the $\gamma^{\prime} 1000 \mathrm{NR}$ c precipitates (dark red, Figure 14b) is longer than the one of the $\gamma^{\prime}{ }_{1000 \mathrm{R}}$ (blue, Figure 14a) and $\gamma^{\prime}{ }_{1000 \mathrm{NR}}$ (light red, Figure 14b) precipitates.

After cooling down to $400{ }^{\circ} \mathrm{C}$, the $\gamma^{\prime}{ }_{1000 \mathrm{R}}$ precipitates evolved into the $\gamma^{\prime}{ }_{400 \mathrm{R}}$ (Figure 7(c, e), Figure 8a, Figure 14d, Figure 15(a, c, e)). Notably, the volume fraction increased from $21 \%$ to $30 \%$ (Figure 15a). However, the mean equivalent diameter surprisingly decreased from $168 \mathrm{~nm}$ to $160 \mathrm{~nm}$. This may come from the fact that some $\gamma^{\prime}{ }_{1000 \mathrm{R}}$ start to present protrusions/morphological instabilities, which suggests that they afterwards subdivide and yield several smaller $\gamma_{400 \mathrm{R}}^{\prime}$ precipitates. Another explanation is that new secondary $\gamma^{\prime}$ precipitates would have nucleated and grown during the cooling from 1000 ${ }^{\circ} \mathrm{C}$ to $400{ }^{\circ} \mathrm{C}$. Then they would grow during a shorter time at lower temperatures and thus be smaller than their more mature counterparts and thus decrease the mean equivalent diameter. Similarly in the unrecrystallized area, the $\gamma^{\prime}{ }_{1000 \mathrm{NR}}$ precipitates evolved into the $\gamma^{\prime}{ }_{400 \mathrm{NR}}$ (Figure $7(\mathrm{~d}, \mathrm{f})$, Figure 14e, Figure 15(b, d, f)) and the $\gamma^{\prime}{ }_{1000 \mathrm{NR}} \mathrm{c}$ precipitates evolved into the $\gamma^{\prime}{ }_{400 \mathrm{NR} c}$ (Figure 7(d, f), Figure 8b, Figure 14e, Figure 15(b, d, f)). Notably, the volume fraction increased from $19.5 \%\left(\gamma^{\prime}{ }_{1000 \mathrm{NR}}\right)$ to $32 \%\left(\gamma_{400 \mathrm{NR}}^{\prime}\right)$ (Figure 15a). Another notable feature is the appearance of tertiary precipitates in both recrystallized (Figure 8a) and unrecrystallized (Figure 8b) areas, as a result of the higher equilibrium volume fraction as the temperature decreases [25], promoting a stronger driving force for nucleation. In the unrecrystallized area, the wider gaps between the 
$\gamma^{\prime}{ }_{400 \mathrm{NR} \text { c }}$ precipitates compared to the $\gamma^{\prime}{ }_{400 \mathrm{R}}$ and $\gamma^{\prime}{ }_{400 \mathrm{NR}} \mathrm{t}$ ones led to a lower depletion of (Al, Ti) solid solution atoms in such gaps. This local higher amount of (Al, Ti) favored a

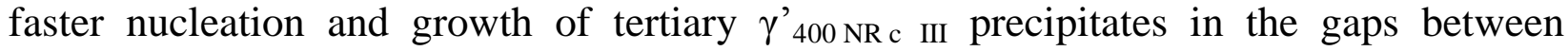
$\gamma^{\prime} 400 \mathrm{NRc}$ ones, compared to the tertiary $\gamma^{\prime}{ }_{400 \mathrm{R} \mathrm{III}}$ and $\gamma^{\prime} 400 \mathrm{NR} \mathrm{tIII}$ precipitates in the gaps between $\gamma^{\prime} 400 \mathrm{R}$ and $\gamma^{\prime}{ }_{400 \mathrm{NR} \mathrm{t} \text { III }}$ ones.

\section{Conclusion and perspectives}

The coupling between post-dynamic recrystallization and $\gamma^{\prime}$ precipitation during cooling after hot deformation was demonstrated here based on a hot compression test designed on that purpose.

Main conclusions are summarized as follows.

(1) The $\gamma^{\prime}$ precipitation occurs even if the material is water-quenched right after deformation.

(2) Post-dynamic recrystallization and $\gamma^{\prime}$ precipitation are concomitant during the slow cooling.

(3) In the unrecrystallized grains, the $\gamma^{\prime}$ precipitation starts sooner than in the recrystallized grains, due to the higher dislocation content acting as highdiffusivity paths for the diffusion (Al, Ti) solute atoms.

(4) The $\gamma^{\prime}$ precipitate size is homogeneous in the recrystallized grains and heterogeneous in the unrecrystallized grains. Such heterogeneity arises as alternate arms/bands of thin and coarse $\gamma^{\prime}$ precipitates following the substructures orthogonal to the compression direction

(5) The migrating recrystallization front dissolves $\gamma^{\prime}$ precipitates of the consumed unrecrystallized areas. Then coherent discontinuous and/or continuous re-precipitation occurs in the recrystallized side.

The mean teaching from that work is that post-dynamic recrystallization and the $\gamma^{\prime}$ precipitation are concomitant. The $\gamma$ ' precipitation does not prevent the progression of post-dynamic recrystallization. The precipitation state obtained in recrystallized grains 
after slow cooling can arise from either direct precipitation in already formed recrystallized grains or from a dissolution/re-precipitation process at the moving recrystallization front.

\section{Acknowledgments}

This project was carried out in the framework of OPALE industrial chair funded by French National Agency for scientific Research ANR and the Safran group. The Safran Aircraft Engines company supplied the hot-compression samples. The authors are grateful for the help of G. Fiorucci in the development of the experimental set up for slow cooling and quenching at CEMEF.

\section{References}

[1] A. J. Porter and B. Ralph, Mater. Sci. Eng., 1983, vol. 59, pp. 69-78.

[2] X. M. Chen, Y. C. Lin, M. S. Chen, H. B. Li, D. X. Wen, J. L. Zhang and M. He, Mater. Des., 2015, vol. 77, pp. 41-49.

[3] Y. C. Lin, J. Deng, Y.-Q. Jiang, D.-X. Wen and G. Liu, Mater. Des., 2014, vol. 55, pp. 949-957.

[4] A. Etaati et D. K., Mater. Chem. Phys., 2013, vol. 140, pp. 208-215.

[5] Y. Ning, M. W. Fu and X. Chen, Mater. Sci. Eng., 2012, vol. 540, pp. 164-173.

[6] D.-X. Wen, Y. C. Lin, H.-B. Li, X.-M. Chen, D. J. and L. L.-T., Mater. Sci. Eng., 2014, vol. 591, pp. 183-192.

[7] X.-M. Chen, Y. C. Lin, D.-X. Wen, J.-L. Zhang and M. He, Mater. Des., 2014, vol. 57, pp. 568-577.

[8] X. Tang, B. Wang, H. Ji, X. Fu et W. Xiao, Mater. Sci. Eng., 2016, vol. 675A, pp. 192-203.

[9] L. X. Zhou and T. N. Baker, Mater. Sci. Eng., 1995, vol. 196, pp. 89-95.

[10] R. P. Guest and S. Tin, Proceedings of the 6th International Symposium on Superalloys 718, 625, 706 and Derivatives, Pittsburgh, PA, USA, 17-20 May 2005.

[11] A. Devaux, A. Helstroffer, J. Cormier and F. Pettinari-Sturmel, 8th International Symposium on Superalloy 718 and Derivatives, 2014, The Minerals, Metals \& Materials Society.

[12] C. Slama and M. Abdellaoui, J. Alloys Compd., 2000, vol. 306, pp. 277-284.

[13] M. Cozar and A. Pineau, Metall. Trans., 1973, vol. 4, pp. 47-59. 
[14] F. Masoumi, M. Jahazi, D. Shahriari and J. Cormier, J. Alloys Compd., 2016, vol. 658, pp. 988-995.

[15] A. Devaux, L. Berglin, L. Thebaud, R. Delattre, C. Crozet and O. Nodin, MATEC Web of conference, 2014, Vols. 14, 01004.

[16] F. Masoumi, D. Shahriari, M. Jahazi, J. Cormier and A. Devaux, Sci. Rep., 2015, vol. 5:28650.

[17] K. Teichmann, C. D. Marioara, S. J. Andersen and K. Marthinsen, Metall. Mater. Trans., 2012, vol. 43A, pp. 4006-4014.

[18] G. Trotter, G. Rayner, I. Baker and P. R. Munroe, Intermetallics, 2014, vol. 53, pp. 120-128.

[19] L. Mataveli Suave, J. Cormier, P. Villechaise, A. Soula, Z. Hervier, D. Bertheau and D. Laigo, Metall. Mater. Trans., 2014, vol. 45A, pp. 2963-2982.

[20] Y. Mei, Y. Liu, C. Liu et H. Li, J. Alloys Compd., 2015.

[21] H. Yang, Z. Li. et M. Huang, Comput. Mater. Sci., 2013, vol. 75, pp. 52-59.

[22] M.-A. Charpagne, «PhD dissertation,» CEMEF, Mines ParisTech, 2016.

[23] D. Turnbull. et R. E. Hoffman, Acta Metall., 1954, vol. 2, p. 419.

[24] J. W. Cahn, Acta Metall., 1957, vol. 5, pp. 169-172.

[25] T.-C. software, Nickel base superalloys.

[26] R. Doherty, Met. Sci., 1982, vol. 16, pp. 1-14.

[27] V. Randle et B. Ralph, Acta Metall., 1986, vol. 34, pp. 891-898.

[28] A. J. Porter, J. Mater. Sci., 1981, vol. 16, pp. 707-713.

[29] H. Lia, F. Yea, T. Zhaoa, T. Caoa, F. Xub, Q. Xua, Y. Wangb, C. Chenga et X. Mina, Mater. Sci. Eng., 2018, vol. 714A, pp. 172-178.

[30] A. Seret, C. Moussa, M. Bernacki, N. Bozzolo and J. Signorelli, J. Appl. Crystallogr., 2018, p. submitted.

[31] M. Doi and T. Miyazaki, The Minerals, Metals and Materials Society, Superalloys 1984.

[32] M. Doi, D. Miki, T. Moritami et T. Kozakai, The Minerals, Metals and Materials Society, Superalloys 2004.

[33] D. W. Scott, Biometrika, 1979, vol. 66, pp. 605-610.

[34] I. M. Lifshitz et V. V. Slyozov, J. Phys. Chem. Solids, 1961, vol. 19, pp. 35-50.

[35] M. Zouari., R. E. Logé and N. Bozzolo, Metals (open access journal), 2017, vol. 7:476.

[36] R. D. Doherty, D. A. Hughes, F. J. Humphreys, J. J. Jonas, D. Jull Jensen, M. E. Kassner, W. E. King, T. R. McNelley, H. J. McQueen and A. D. Rollett, Mater. Sci. Eng. A, 1997, vol. 238, pp. 219- 
274. 


\section{Figure captions}

Figure 1: thermomechanical path applied to produce the five studied samples.

Figure 2: SEM characterization of the sample q1125 (the compression direction is vertical). BSE images showing (a) an overview of the microstructure,

(b) recrystallized and unrecrystallized areas (zoom into the rectangular area shown on (a))

SE images showing $\gamma^{\prime}$ precipitates in (c) recrystallized and (d) unrecrystallized areas.

Figure 3: BSE images of the sample q1075 (the compression direction is vertical)

showing (a) an overview of the microstructure, (b) recrystallized and unrecrystallized areas,

(c) bands of statically recrystallized grains during the cooling

surrounded by unrecrystallized areas,

(d) a band of statically recrystallized grains during the cooling

and $\gamma^{\prime}$ precipitates in the surrounding unrecrystallized areas

Figure 4: SE images of the sample q1075 (the compression direction is vertical), showing

(a) $\gamma^{\prime} 1075_{\mathrm{NR}}$ precipitates in unrecrystallized areas surrounding recrystallized grains,

(b) $\gamma^{\prime} 1075_{\mathrm{NR}}$ precipitates in an unrecrystallized area,

(c) $\gamma^{\prime}$ WQ precipitates inside a statically post-dynamically recrystallized grain resulting from the water quench.

Figure 5: BSE images of the sample q1000 (the compression direction is vertical), showing

(a) an overview of the microstructure, (b) recrystallized and unrecrystallized areas, (c, e) $\gamma^{\prime} 1000_{\mathrm{R}}$ in an recrystallized area,

$(\mathrm{d}, \mathrm{f})$ alternate horizontal arms/bands of $\gamma^{\prime} 1000 \mathrm{NR} \mathrm{t}$ and $\gamma^{\prime} 1000_{\mathrm{NR}} \mathrm{c}$ in an unrecrystallized area. 
Figure 6: SE images of the sample q1000 (the compression direction is vertical) showing (a) $\gamma^{\prime}{ }_{1000 \mathrm{R}}$ and (b) $\gamma^{\prime} 1000 \mathrm{NR}$ c precipitates in an unrecrystallized area.

Figure 7: BSE images of the sample q400 (the compression direction is vertical), showing (a) an overview of the microstructure, (b) recrystallized and unrecrystallized areas, (c, e) $\gamma^{\prime} 400_{\mathrm{R}}$ precipitates in an recrystallized area, $\left(d\right.$, f) alternate horizontal arms/bands of $\gamma^{\prime} 400_{\mathrm{NR}}$ and $\gamma^{\prime} 400_{\mathrm{NR}} \mathrm{c}$ in an unrecrystallized area.

Figure 8: SE images of the sample q400 (the compression direction is vertical) showing (a) $\gamma^{\prime} 400_{R}, \gamma^{\prime} 400_{\mathrm{R} \mathrm{III}}$ in a recrystallized area,

(b) $\gamma^{\prime} 400_{\mathrm{NR}}$ and $\gamma^{\prime} 400_{\mathrm{NR} \text { c III }}$ precipitates in an unrecrystallized area.

Figure 9: BSE images of the sample $\mathrm{q}_{400}$ (the compression direction is vertical) showing (a) $\gamma^{\prime}{ }_{400 \mathrm{R}}$ and $\gamma^{\prime}{ }_{400 \mathrm{NR} \mathrm{c}}$ precipitates on both sides of the recrystallization front (dashed magenta curve) and (b) $\gamma_{400 \mathrm{RF}}$ precipitates on the recrystallization front and $\gamma^{\prime}{ }_{400 \mathrm{R} \text { bigger }}$ precipitates near the recrystallized front in the recrystallized area.

Figure 10: BSE images in the sample $\mathrm{q}_{400}$ along on the recrystallization front, showing both recrystallized (bright) and unrecrystallized (dark) areas and $\gamma^{\prime}{ }_{400 \mathrm{RF}}$ precipitates on the recrystallization front: (a) 3 localizations of the $\gamma^{\prime}$ phase ((1) in the recrystallized area, (2) in both recrystallized and unrecrystallized areas, (3) in the unrecrystallized area); (b) $\gamma^{\prime}{ }_{400 \mathrm{RF}}$ precipitate in the recrystallized area; (c) $\gamma^{\prime}$ localization in both recrystallized and unrecrystallized areas where (5) is the part in the recrystallized area, and scattered thinner $\gamma$ ' precipitates in the recrystallized area (blue rectangle).

Figure 11: in sample q400, (a) corresponding crystallographic orientation maps on top of BSE image showing $\gamma^{\prime} 400_{\mathrm{R}}, \gamma^{\prime} 400_{\mathrm{NR}} \mathrm{c}, \gamma^{\prime} 400_{\mathrm{RF}}$ and $\gamma^{\prime} 400_{\mathrm{R} \text {, bigger }}$ precipitates, (b) definition of the inverse pole figure, 
color-coding is relative to the (vertical) compression direction

(c) KAM map in degree of the same area unmagnified 4 times (matches Figure 9a).

Figure 12: (a) recrystallized volume fraction and (b) mean recrystallized grain size as a function of quenching temperature.

Figure 13: simplified nomenclature of $\gamma^{\prime}$ precipitate types.

Figure 14: Density histograms (bin width from Scott rule ) of equivalent diameter of $\gamma^{\prime} 400_{\mathrm{R}}$ and $\gamma^{\prime} 400_{\mathrm{NR}}$ per area unit of the different $\gamma^{\prime}$ precipitates populations, rows correspond to quenching temperatures (a) $1075^{\circ} \mathrm{C}$, (b, c) $1000{ }^{\circ} \mathrm{C}$ and (d, e) $400{ }^{\circ} \mathrm{C}$. In (e) the leftmost bar of $\gamma^{\prime} 400_{\mathrm{NR} \text { c III }}$ distribution goes above $40 \mu \mathrm{m}^{-2}$ so it is cut at $5 \mu \mathrm{m}^{-2}$ to keep $\gamma^{\prime} 400_{\mathrm{NR}}, \gamma^{\prime} 400_{\mathrm{NR} \text { t III }}$ and $\gamma^{\prime} 400_{\mathrm{NR} \text { c }}$ distributions visible.

Figure 15: $\gamma^{\prime}$ volume fraction in the (a) recrystallized and (b) unrecrystallized areas, mean equivalent diameter of $\gamma^{\prime}$ precipitates in the (c) recrystallized and (d) unrecrystallized areas, number of $\gamma^{\prime}$ precipitates per unit area in the (e) recrystallized and (f) unrecrystallized areas as a function of quenching temperature. 